ARTICLE

\title{
The mechanism of activation of the actin binding protein EHBP1 by Rab8 family members
}

\author{
Amrita Rai (1) ${ }^{1 凶}$, Nathalie Bleimling ${ }^{1}$, Ingrid R. Vetter ${ }^{2} \&$ Roger S. Goody ${ }^{1 凶}$
}

EHBP1 is an adaptor protein that regulates vesicular trafficking by recruiting Rab8 family members and Eps15-homology domain-containing proteins 1/2 (EHD1/2). It also links endosomes to the actin cytoskeleton. However, the underlying molecular mechanism of activation of EHBP1 actin-binding activity is unclear. Here, we show that both termini of EHBP1 have membrane targeting potential. EHBP1 associates with $\mathrm{PI}(3) \mathrm{P}, \mathrm{PI}(5) \mathrm{P}$, and phosphatidylserine via its $\mathrm{N}$-terminal $\mathrm{C} 2$ domain. We show that in the absence of Rab8 family members, the C-terminal bivalent Mical/EHBP Rab binding (bMERB) domain forms an intramolecular complex with its central calponin homology $(\mathrm{CH})$ domain and auto-inhibits actin binding. Rab8 binding to the bMERB domain relieves this inhibition. We have analyzed the CH:bMERB auto-inhibited complex and the active bMERB:Rab8 complex biochemically and structurally. Together with structure-based mutational studies, this explains how binding of Rab8 frees the $\mathrm{CH}$ domain and allows it to interact with the actin cytoskeleton, leading to membrane tubulation.

\footnotetext{
${ }^{1}$ Department of Structural Biochemistry, Max Planck Institute of Molecular Physiology, Otto-Hahn-Strasse 11, 44227 Dortmund, Germany. ${ }^{2}$ Department of Mechanistic Cell Biology, Max Planck Institute of Molecular Physiology, Otto-Hahn-Strasse 11, 44227 Dortmund, Germany. ${ }^{凶}$ email: amrita.rai@mpidortmund.mpg.de; goody@mpi-dortmund.mpg.de
} 
E HBP1 was originally identified as an Eps15-homology domain-containing protein $1 / 2$ (EHD1/2) interacting partner that plays a central role in GLUT4 transport and couples endocytic vesicles to the actin cytoskeleton ${ }^{1,2}$. EHBP1 co-localizes with the actin cytoskeleton and overexpression of either EHBP1 or EHD2 leads to extensive actin reorganization $^{2}$. Disruption of EHBP1/EHDs by siRNA leads to inhibition of transferrin endocytosis and GLUT4 transportation ${ }^{2}$. The Ras superfamily GTPase Rab10 has also been shown to regulate the translocation of GLUT4 in adipocytes ${ }^{3}$. In our previous work, we showed that EHBP1 is an effector molecule for Rab8 family members, including Rab10, and forms complexes with 1:1 stoichiometry ${ }^{4,5}$. Recent work has also shown that a Rab10-EHBP1-EHD2 trimeric complex plays a crucial role in lipid droplet engulfment during lipophagy in hepatocytes $^{6}$. Moreover, C. elegans EHBP1 promotes endosomal tubulation by linking the membrane lipid PI $(4,5) \mathrm{P} 2$ to the actin cytoskeleton and this interaction is enhanced upon Rab10 binding ${ }^{7}$.

Apart from having roles in vesicular trafficking and autophagy, EHBP1 is implicated in early development and cancer. In C. elegans, EHBP1 depletion leads to an endocytic recycling defect in the intestine and in nonpolarized germline cells and the phenotype was recapitulated upon Rab8/10 deletion ${ }^{8}$. Drosophila EHBP1 has been shown to play an essential role in eye development by regulating the exocytosis of Scabrous, a positive regulator of Notch signaling 9 . Notch signaling has been implicated in metastatic prostate cancer, and a genome-wide SNP association study shows that EHBP1 is associated with aggressive disease ${ }^{10-13}$. EHBP1 controls the invasiveness of PTEN-positive prostate cancer cells and is essential for the anti-invasive effect of the drug atorvastatin ${ }^{14}$.

Despite having information on EHBP1 at the functional level, convincing biochemical data on EHBP1 activation are missing. In this work, we have identified and characterized an autoinhibited state of human EHBP1, which is mediated by an intramolecular association between the $\mathrm{CH}$ domain and the bMERB domain. We have elucidated the structure of the $\mathrm{CH}$ domain in complex with the bMERB domain, providing an explanation for the specificity of EHBP $1_{\text {bMERB }}$ toward its $\mathrm{CH}$ domain. Transient kinetic experiments show that the binding of Rab8 family members to the bMERB domain releases the $\mathrm{CH}$ domain. Furthermore, we have solved the crystal structure of the bMERB domain in complex with human Rab8a. Structural analyses supported by mutagenesis and biochemical experiments identify key residues for the interaction and explain why the generation of a stable CH-bMERB-Rab8 ternary complex is not possible. Our biochemical and structural data suggest that the interaction between the C-terminal bMERB domain and the central $\mathrm{CH}$ domain has a regulatory role in the function of EHBP1 and binding of Rab8 family members to the bMERB domain releases the $\mathrm{CH}$ domain, which can then interact with the actin cytoskeleton.

\section{Results}

Domain architecture and localization of EHBP1. EHBP1 consists of an N-terminal $\mathrm{C} 2$ domain, a central $\mathrm{CH}$, a C-terminal bMERB domain, and a CaaX box at the C-terminus that is a substrate for FTase ${ }^{4}$. The UniPort database has reported three EHBP1 isoforms and for biochemical studies, the domain boundaries are taken from isoform 1 (Q8NDI1-1), whereas for cellular localization experiments, fluorescent constructs are based on isoform 3 (Q8NDI1-3) (Fig. 1a). Previously, we have reported that the bMERB domain, together with the CaaX box, is sufficient to target an EGFP-fusion protein to the endosome and co-localize with active Rab8/104. Here, we show that the full-length protein, as well as the construct lacking the NT-C2 domain, is targeted to structures that appear to be endosomes. Surprisingly, the EGFP$\mathrm{EHBP} 1_{\triangle \mathrm{CaaX}}$ construct is cytosolic, suggesting that even in the full-length background, the CaaX box is indispensable for endosomal localization. However, this could be due to the presence of the N-terminal EGFP tag, which could hinder membrane association via the NT-C2 domain. To rule out this possibility, we expressed an isolated NT-C2 EGFP (C-terminal) fusion construct and showed that this construct is cytosolic as well as having the potential to associate with membranous structures (Fig. 1b). Thus, our localization data suggest that both termini of EHBP1 have membrane targeting potential. Further, we could show that the full-length EHBP1 co-localizes with Rab8/10 active constructs (Fig. 1c, d).

Intrigued by the observation that the NT-C2 domain associates with membranes, we investigated the lipid-binding properties of the domain by performing a protein-lipid overlay assay using the His6-MBP-NT-C2 domain fusion protein. The NT-C2 domain of EHBP1 is a member of a unique but not well studied NT-C2 domain family ${ }^{15}$, and in general, most of the $\mathrm{C} 2$ domain family members are known to interact with phospholipids directly $7,15,16$. Since most of the C2 domain family members have been reported to be regulated by $\mathrm{Ca}^{2+}$ ions, we performed the experiments in the presence or absence of $\mathrm{Ca}^{2+}$ ions. The results obtained indicated that the NT-C2 domain of EHBP1 binds to phosphatidylserine in the presence of $\mathrm{Ca}^{2+}$ but also binds PI(3)P and PI (5) $\mathrm{P}$ in a $\mathrm{Ca}^{2+}$ independent manner (Fig. 1e). Additional biochemical experiments are required to validate and extend these initial observations.

C-terminal high affinity Rab-binding site of bMERB domain. Previously, we reported that the EHBP1 bMERB domain preferentially binds to Rab8 family members ${ }^{4}$. In this work, we have

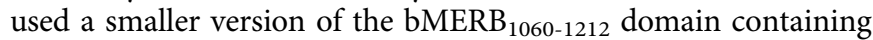
all three predicted $\alpha$-helices ${ }^{4}$, which, consistent with our prior work, forms a stable complex with Rab8a with a similar affinity to the longer bMERB b $_{104-1220}$ construct. Earlier, we reported that some bMERB family members have two Rab-binding sites, a high-affinity C-terminal binding site, and a lower or similar affinity $\mathrm{N}$-terminal binding site $\mathrm{e}^{4,5}$. However, in the case of the EHBP1 bMERB domain, we observed only a single-binding site ${ }^{4}$. To localize the exact binding site, we made two deletion constructs in which either the $\mathrm{N}$ or the $\mathrm{C}$-terminal helix was deleted (Fig. 2a, insets). Both the full-length as well as the N-terminally truncated constructs form stable complexes with Rab8a as observed by analytical size exclusion chromatography (aSEC) experiments. Further, isothermal titration calorimetry (ITC) measurements show that both bMERB constructs bind to Rab8a: GppNHp with a $K_{\mathrm{D}}$ value of $0.3 \mu \mathrm{M}$ (Fig. 2b). In contrast, we could not detect any interaction with the (potential) $\mathrm{N}$-terminal low-affinity binding site.

Next, we independently measured the association $\left(k_{\text {on }}\right)$ and dissociation rate $\left(k_{\text {off }}\right)$ constants for $K_{\mathrm{D}}$ calculation $\left(K_{\mathrm{D}}=\right.$ $\left.k_{\text {off }} / k_{\text {on }}\right)$. For $k_{\text {on }}$ measurements, association kinetics of Rab8a loaded with fluorescent $2^{\prime} 3^{\prime}$-O-(N-methyl-anthraniloyl) mantGppNHp were monitored with increasing concentrations of the bMERB $_{1060-1212}$ domain using a stopped-flow apparatus. $k_{\text {on }}$ for Rab8 $\mathrm{a}_{\text {mantGppNHp }}$ is $2.79 \times 10^{7} \mathrm{M}^{-1} \mathrm{~s}^{-1}$ and the intercept on the $\mathrm{y}$-axis yielded the $k_{\text {off }}\left(13.4 \mathrm{~s}^{-1}\right)$ (Fig. 2c). Direct $k_{\text {off }}$ was determined by the displacement of the Rab8a $a_{\text {mantGppNHp from }}$ the bMERB ${ }_{1060-1212}$ domain by an excess of Rab8a $a_{\text {GppNHp }}, k_{\text {off }}$ of $13.8 \mathrm{~s}^{-1}$ was observed (Fig. $2 \mathrm{~d}$ ) and $K_{\mathrm{D}}$ value of $0.48 \mu \mathrm{M}$ was calculated, in reasonable agreement with the value of $0.31 \mu \mathrm{M}$ obtained in ITC experiments. 
a

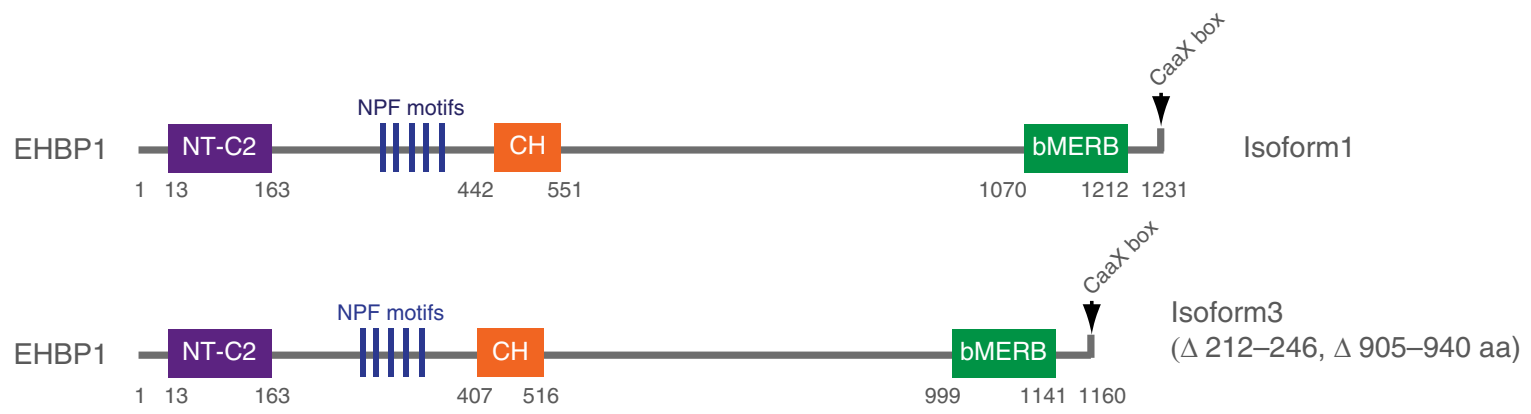

b

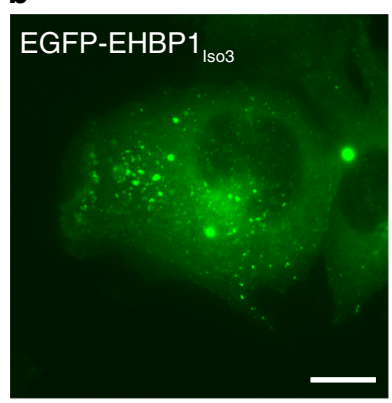

C
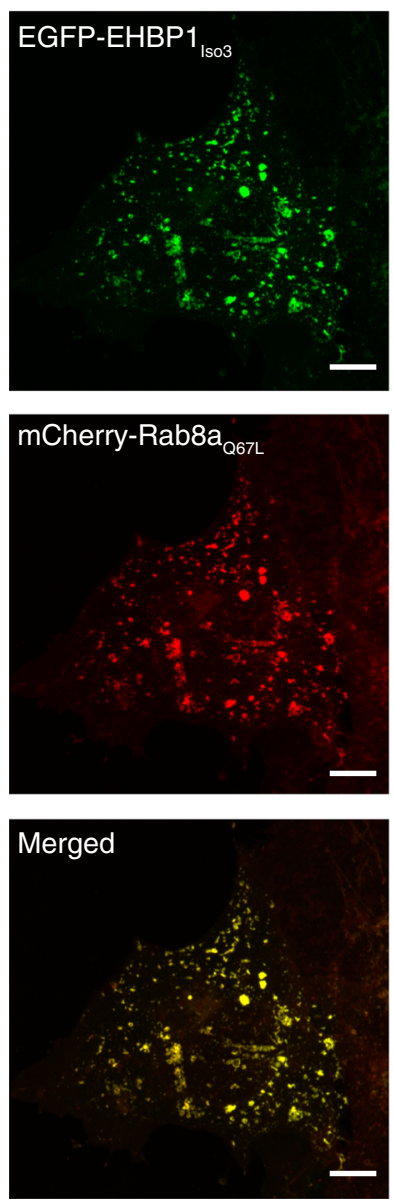

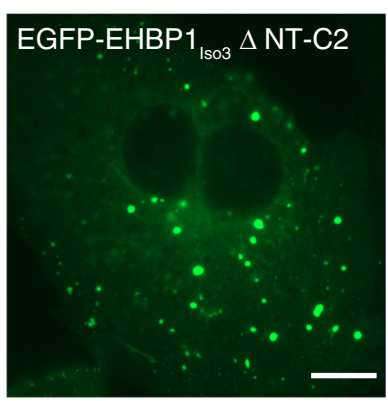

d
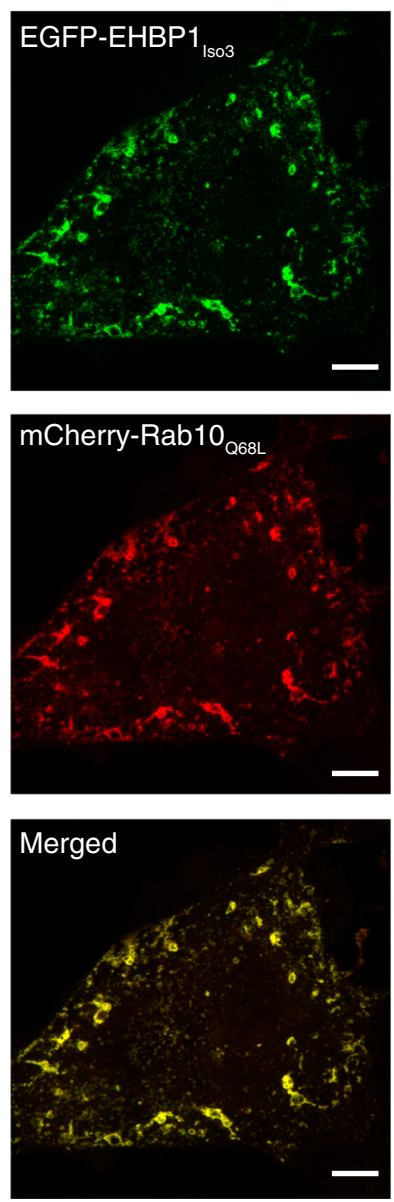

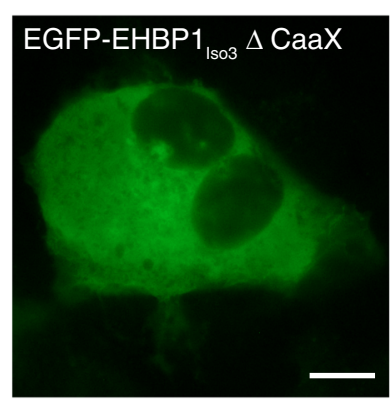

e
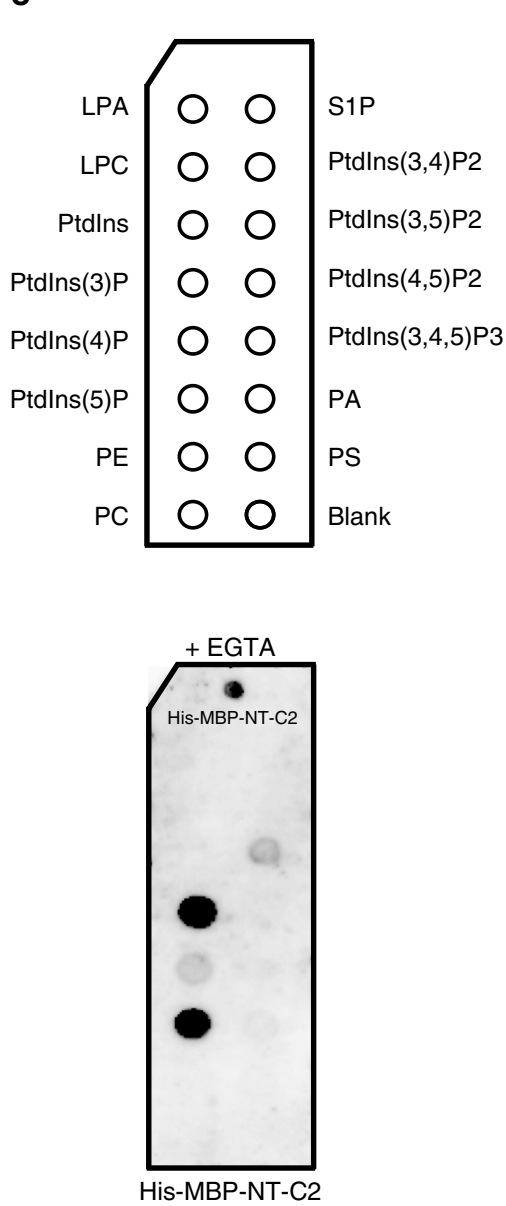
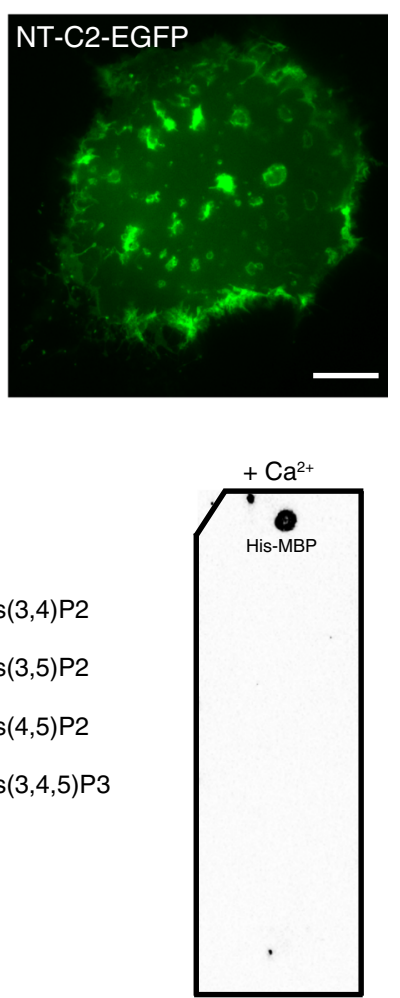

His-MBP

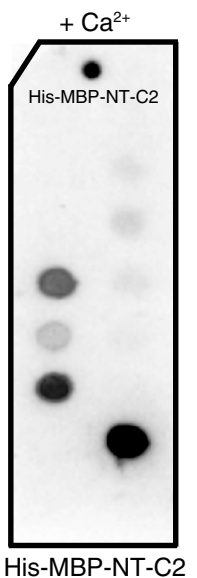

Phosphomimetic mutation of Rab8/10 switch II threonine. LRRK2, a serine/threonine kinase phosphorylates threonine of switch II of Rab8 $\mathrm{a}_{\mathrm{T} 72} / 10_{\mathrm{T} 73}$. Phosphorylated Rabs are GDI resistant, thus increasing their lifetime on the membrane ${ }^{17,18}$. Further, phosphorylation also increases Rab8a/10 binding to the effector proteins RILPL1/L2 ${ }^{18}$. Structure-based sequence alignment shows that the switch II threonine of Rab8a/10 does not directly interact with Micall $l_{\text {bMERB }}$ and Mical $\mathrm{CL}_{\mathrm{bMERB}}{ }^{4}$ (Fig. 2e). However, it is still unknown whether phosphorylation of Rab8a/10 has any effect on the EHBP $1_{\text {bMERB }}$ interaction. Therefore, we prepared the phosphomimetic mutants Rab8 $\mathrm{a}_{\mathrm{T} 72 \mathrm{E}} / 10_{\mathrm{T} 73 \mathrm{E}}$ by site-directed mutagenesis and checked for complex formation 
Fig. 1 Domain architecture and cellular localization of human EHBP1. a EHBP1 contains an N-terminal C2-like domain (NT-C2), a central CH (calponin homology) domain, and a C-terminal a coiled-coil bMERB (bivalent Mical/EHBP Rab binding) domain. At the end of the bMERB domain, EHBP1 also has a C-terminal prenylation motif (CaaX box). In addition to these domains, EHBP1 harbors five NPF motifs. Isoform 1 is composed of 1231 amino acids and isoform 3 lacks residues 212-246 and residues 905-940. b Cellular localization of different EGFP tagged EHBP1 constructs. Scale bar: $10 \mu$ m. c, d EGFPEHBP1 shows strong co-localization with mCherry tagged Rab8a $\mathrm{Q}_{\mathrm{Q} 67 \mathrm{~L}}$ and mCherry tagged Rab10 $\mathrm{Q}_{\mathrm{Q} 8 \mathrm{~L}}$. Scale bar: $10 \mu \mathrm{m}$. Experiments were repeated at least three times independently with similar results. e Lipid-binding activity of NT-C2 domain of EHBP1. Lipid spots present on the PIP strip are indicated in the left panel. LPA Lysophosphatidic Acid, LPC lysophosphatidylcholine, Ptdlns phosphatidylinositol, PI(3)P phosphatidylinositol-3-phosphate, PI(4)P phosphatidylinositol-4-phosphate, PI(5)P phosphatidylinositol-5-phosphate, PE phosphatidylethanolamine, PC phosphatidylcholine, S1P sphingosine-1phosphate, $\mathrm{PI}(3,4) \mathrm{P} 2$ phosphatidylinositol-3,4-bisphosphate, $\mathrm{PI}(3,5) \mathrm{P} 2$ phosphatidylinositol-3,5-bisphosphate, $\mathrm{PI}(4,5) \mathrm{P} 2$ phosphatidylinositol-4,5bisphosphate, PI(3,4,5)P3 phosphatidylinositol-3,4,5-trisphosphate, PA phosphatidic acid, PS phosphatidylserine. Experiments were repeated at least three times independently with similar results.

with the bMERB domain by aSEC/ITC experiments (Fig. $2 \mathrm{f}$ and Supplementary Fig. 1). No effect of phosphomimetic mutations of Rab8a/10 on the EHBP $1_{\text {bMERB }}$ interaction was observed.

$\mathrm{CH}$ and bMERB domain association and release by Rab8. It has been suggested that some bMERB family members exist in an autoinhibited state in the absence of Rab and that the bMERB domains have to be released or exposed for activation to occur ${ }^{19-24}$. Since it was was difficult to investigate a possible intramolecular interaction between the $\mathrm{CH}$ and bMERB domains of EHBP1 using constructs containing both domains, we examined the interaction between the separately purified bMERB and $\mathrm{CH}$ domains of EHBP1, initially employing aSEC experiments. Clear complex formation with the $\mathrm{CH}$ domain was observed for the construct lacking the C-terminal helix of the bMERB domain (Fig. 3a). However, in the case of the full-length construct, only a partial shift in the $\mathrm{CH}$ domain peak was observed, indicating a weaker equilibrium between free and bMERB-bound $\mathrm{CH}$ domains. No complex formation was observed for the construct lacking the $\mathrm{N}$ terminal helix (Fig. 3a). Using ITC measurements, binding was observed between full-length bMERB domain and $\mathrm{CH}$ domains and similar to Rab8a, CH domain binding to bMERB domain is an enthalpy driven process with a $K_{\mathrm{D}}$ value of $1.2 \mu \mathrm{M}$ and stoichiometry of 1:1. The C-terminally truncated construct showed a slightly higher affinity $\left(K_{\mathrm{D}}=0.78 \mu \mathrm{M}\right)$, whereas no binding was observed for the construct lacking the $\mathrm{N}$-terminal helix, clearly indicating that helices 1 and 2 constitute the $\mathrm{CH}$-binding site (Fig. 3b).

Using transient kinetic measurements, we determined the $k_{\text {on }}$ and $k_{\text {off }}$ rate constants for the $\mathrm{CH}$ and full-length bMERB domain interaction. The observed pseudo first oder association rates of Cy3-CH were plotted against increasing concentrations of the bMERB domain and a $k_{\text {on }}$ of $2.76 \times 10^{7} \mathrm{M}^{-1} \mathrm{~s}^{-1}$, while $k_{\text {off }}$ was $103.7 \mathrm{~s}^{-1}$ as obtained from the y-axis intercept (Fig. 3c). $k_{\text {off }}$ was also measured directly by displacing $\mathrm{Cy} 3-\mathrm{CH}$ from the bMERB domain by mixing with an excess of unlabeled $\mathrm{CH}$ domain, leading to a value of $117 \mathrm{~s}^{-1}$ (Fig. 3d). These values led to a calculated $K_{\mathrm{D}}$ value of $3.75-4.23 \mu \mathrm{M}$. This is higher than the value obtained by ITC, suggesting some interference with bMERB binding by the Cy3 label. We note that the association rate constant for $\mathrm{CH}$ and Rab8a binding to bMERB is nearly identical, whereas the $k_{\text {off }}$ for $\mathrm{CH}$ is ca. ten times higher than for Rab8a (Fig. 2c, d).

To test whether binding of Rab8a to the bMERB domain can release the $\mathrm{CH}$ domain, we generated the Cy3-CH:bMERB complex and mixed it rapidly with an excess of Rab8a. This led to an increase in fluorescence intensity, indicating that Rab8a can indeed displace the $\mathrm{CH}$ domain and $k_{\text {off }}$ was $162 \mathrm{~s}^{-1}$ (Fig. 3e), which is significantly larger than that for spontaneous dissociation (Fig. 3d), suggesting an active displacement mechanism via a ternary complex between the three proteins.
In similar experiments using different bMERB domains and their respective $\mathrm{CH}$, LIM, or $\mathrm{CH}$-LIM domains, no complex formation was detected using aSEC/ITC experiments (Fig. $3 \mathrm{f}$ and Supplementary Fig. 2).

The $\mathbf{C H}$ domain interacts with actin filaments. To serve as an actin-binding domain $(\mathrm{ABD})$, a tandem repeat of $\mathrm{CH} 1$ and $\mathrm{CH} 2$ is usually required ${ }^{25}$. The $\mathrm{CH} 1$ domain directly interacts with $\mathrm{F}$ actin, while $\mathrm{CH} 2$ plays a supporting role ${ }^{26}$. The human EHBP1 $\mathrm{CH}$ domain is quite similar to the $\mathrm{CH} 2$ domain of alpha-actinin 4 (36\% identity), which usually has a lower actin-binding affinity; however, the $C$. elegans $\mathrm{CH}^{\mathrm{EHBP} 1}$ domain was shown to interact with actin filaments ${ }^{7}$. Using actin co-sedimentation assays, we could demonstrate an interaction with the human EHBP1 $\mathrm{CH}$ domain, with a $K_{\mathrm{D}}$ value of $9.34 \pm 1.86 \mu \mathrm{M}$ (Fig. $4 \mathrm{a}, \mathrm{b}$ ). The affinity is relatively high for a single $\mathrm{CH} 2$ domain; for alphaactinin and utrophin isolated $\mathrm{CH} 2$ domains a $K_{\mathrm{D}}$ of $>1000 \mu \mathrm{M}$ was reported 27,28 .

A similar interaction of the $\mathrm{CH}$ domain from Micals/Mical-like family members could not be detected (Fig. 4c).

The overall structure of the CH:bMERB complex. Although crystals of the EHBP1 CH:bMERB diffracting to $4.0 \AA$ were obtained, these were twinned and the crystal quality could not be improved. Since we had noted earlier that helices 1 and 2 of the bMERB domain are sufficient to form a complex with the $\mathrm{CH}$ domain, we then used the bMERB $\mathrm{H}_{1-2}: \mathrm{CH}$ complex and obtained crystals (SG: P 2 $2_{1}$ ) diffracting to $2.2 \AA$. The structure was solved as described in material and methods (Data and refinement statistics are shown in Supplementary Table 1).

The asymmetric unit contained two copies of the $\mathrm{CH}$ : bMERB $_{\mathrm{H} 1-2}$ complex, sharing the same overall architecture (Supplementary Fig. 3a, b). According to a DALI search ${ }^{29}$ against the protein data bank, the EHBP1 CH domain is most similar to the $\mathrm{CH} 2$ domains of alpha-actinin $4^{30}$ and betaspectrin $^{31}$ (Supplementary Fig. 3c). As expected, the bMERB $\mathrm{H}_{1}$ 2 is composed of two helices and the $\mathrm{CH}$ domain adopts a similar fold to the corresponding free EHBP1 $\mathrm{CH}$ domain (PDB 2D89) ${ }^{32}$ (Supplementary Fig. 3c). The interface of the bMERB $_{\mathrm{H} 1-2}: \mathrm{CH}$ complex shows both hydrophobic and hydrophilic interactions with a buried surface area of $593 \AA^{2}$ (Fig. $4 \mathrm{~d}$, e). Most of the interactions with the $\mathrm{CH}$ domain lie on $\alpha$-helix 2 , with some additional interacting residues provided by $\alpha$ helix 1 (Fig. 4d). An array of hydrophobic residues including L1099, M1103 of $\alpha$-helix 1 and M1116, W1119, F1120 and V1123 from $a$-helix 2 forms a contiguous hydrophobic patch on the bMERB surface with extensive contacts to L534, M537, and Y541 of the C-terminal helix of the $\mathrm{CH}$ domain (Fig. $4 \mathrm{~d}, \mathrm{e}$ ). Besides these hydrophobic interactions, several polar interactions were observed at the CH:bMERB binding interface, including $\mathrm{D} 532^{\mathrm{CH}}-\mathrm{R} 1100, \mathrm{~T} 535^{\mathrm{CH}}-\mathrm{R} 1100, \mathrm{~T} 538^{\mathrm{CH}}-\mathrm{W} 1119$, 

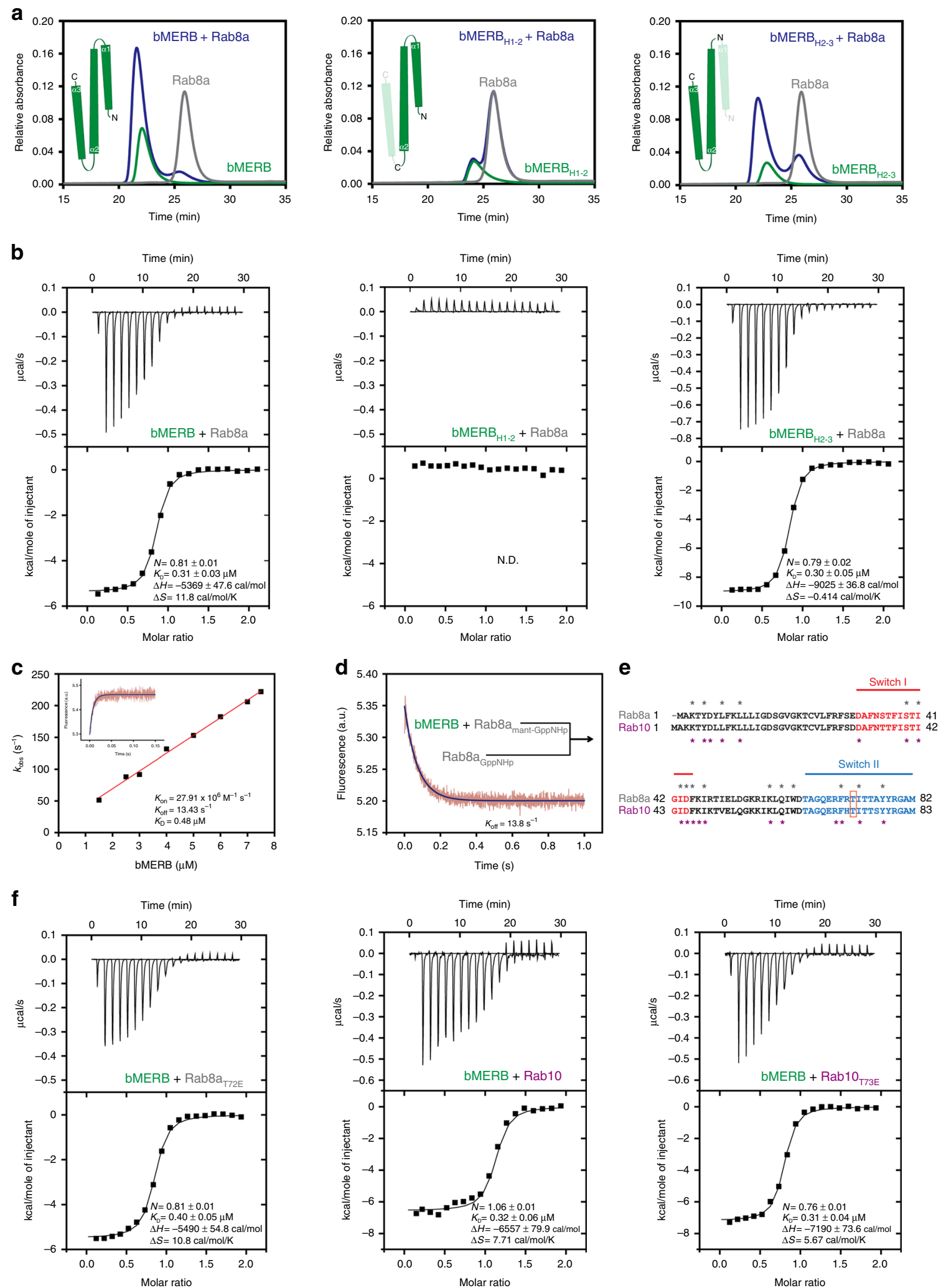

$\mathrm{Y} 541 \mathrm{CH}_{-} \mathrm{N} 1124$, and $\mathrm{Q}_{542} \mathrm{CH}_{-} \mathrm{N} 1127$. The $\mathrm{Y}_{541} \mathrm{CH}$ side chain also forms a hydrogen bond with the backbone carbonyl of F1120, and the R1131 side chain forms another hydrogen bond with the carbonyl of $\mathrm{G} 549^{\mathrm{CH}}$ (Fig. $4 \mathrm{~d}$ inset). Some of the interface residues are conserved in different bMERB family members (Fig. 4f).
Key elements of the CH:bMERB interface. To identify the crucial key residues required for complex formation, we purified a series of $\mathrm{CH}$ as well as bMERB domain mutants and checked their interaction using ITC measurements. Beginning with the Cterminal interacting residues of the $\mathrm{CH}$ domain, we could show that mutation of the conserved D532 to alanine leads to a more 
Fig. 2 Rab8 preferentially binds to the C-terminal Rab-binding site of the bMERB domain. a The bMERB domain (green), GppNHp Rab8a $a_{1-176}$ (gray), and a mixture of both (blue) were loaded onto a Superdex 75 10/300 GL column and monitored for complex formation. Complex formation was observed in the case of the full-length domain (indicated as green helices in the inset) as well as a construct lacking the N-terminal helix, indicating that helices 2-3 are crucial for Rab8a $a_{G p N H p}$ interaction, clearly showing that only the high-affinity C-terminal Rab8 binding site is present in the EHBP1 bMERB domain. b Binding affinities were measured by titrating GppNHp Rab8a $a_{-176}(500 \mu M)$ to the bMERB domain $(50 \mu M)$. Integrated heat peaks were fitted to a one-site-binding model yielding the binding stoichiometry $(\mathrm{N})$, the enthalpy $(\Delta \mathrm{H})$, the entropy $(\Delta \mathrm{S})$, and the dissociation constant $\left(K_{\mathrm{D}}\right)$. The data are representative of at least three repetitions. N.D. denotes not detected. c Observed pseudo first order association rate constants between $0.5 \mu \mathrm{M}$

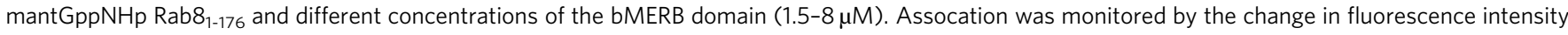
using a stopped-flow apparatus at $25^{\circ} \mathrm{C}$. Association of the bMERB domain with mantGppNHp Rab8 $8_{1-176}$ leads to an increase in intensity. As an example of the data obtained, the association between $0.5 \mu \mathrm{M}$ mantGppNHp Rab8 $8_{1-176}$ and $4 \mu \mathrm{M}$ of the bMERB domain is shown in the inset. $\mathbf{d}$ Dissociation of Rab8a from the bMERB domain was monitored using the decrease of fluorescence after mixing a complex of mantGppNHp Rab8 $a_{1-176}$ with the bMERB domain

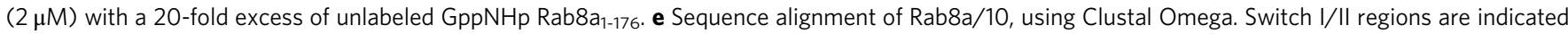
in red and light blue colors, respectively. The residues involved in binding with the Mical CL bMERB domain are denoted by gray (Rab8a) and magenta asterisks (Rab10), and T72/73 phosphorylated by LRRK2 is shown in the orange box. $\mathbf{f}$ Phosphomimetic mutation of switch II threonine does not affect bMERB binding of both Rab8 and Rab10. Binding affinities were measured by ITC experiments. The data are representative of at least three repetitions.

than 40 -fold reduction in binding affinity (Fig. $5 \mathrm{~d}$ ), while mutation of L534 and T538 completely abolishes the interaction with the bMERB domain (Fig. 5e, f). However, mutation of M537, Y541, and Q542 to alanine only led to minor decreases in affinity (Fig. $5 \mathrm{~g}-\mathrm{i}$ ). The side chain of $\mathrm{L} 534^{\mathrm{CH}}$ inserts itself into the pocket created by L1099, R1100, M1103, and M1116 of the bMERB domain. D532, T535, and T538 of the $\mathrm{CH}$ domain stabilize the hydrophobic surface of the bMERB domain, which seems to be crucial for the interaction (Fig. 4d, e and Fig. 5a, b). Sequence alignments of the $\mathrm{CH}$ domain from EHBP1 and Mical family members show that only D532 and L534 are conserved, whereas the essential T538 is not conserved (Supplementary Fig. 4f).

Conversely, we mapped the effect of the continuous hydrophobic surface (Fig. 5b) of the full-length bMERB domain by mutating M1103, M1116, W1119, F1120, and L1099_R1100 (LR motif ${ }^{4}$ to alanine. Each mutation led to a significant decrease in binding affinity with wild type $\mathrm{CH}$ domain (Fig. $5 \mathrm{j}-\mathrm{n}$ ), indicating that indeed the continuous patch of hydrophobic residues is crucial for the interaction (Fig. $5 \mathrm{j}-\mathrm{n}$ and Fig. $4 \mathrm{~d}$, e). Interestingly, sequence alignment of the bMERB domains from EHBP1 and Mical family members shows that the LR motif and total hydrophobicity of the binding interface is quite conserved in EHBP1 and Micals. However, it appears that small changes in the amino acid composition may determine the specificity, as seen for the crucial non-conserved M1103 (Fig. 4e and Supplementary Fig. 3e).

Subsequently, we investigated whether a mutation at the $\mathrm{CH}$ binding site of the bMERB domain has any effect on Rab8 binding and could show that bMERB hydrophobic mutants still form stable complexes with Rab8a with similar affinity (Supplementary Fig. 4). Since we were not able to obtain wild type bMERB:Rab8a crystals, we attempted to crystallize these mutant: Rab8a complexes, finally succeeding with the mutants of the fulllength $\mathrm{bMERB}_{\mathrm{M} 1116 \mathrm{~A}}:$ Rab8a and bMERB $\mathrm{F} 1120 \mathrm{~A}_{\mathrm{A}}:$ Rab8a.

Structure of the bMERB:Rab8a complex. In order to investigate how the binding of Rab8a releases the $\mathrm{CH}$ domain from the bMERB domain, we aimed to determine the structure of a fulllength bMERB domain in complex with Rab8a. We were able to solve the structures of the bMERB $_{M 1116 \mathrm{~A}}:$ Rab8a and bMERB $_{\mathrm{F} 1120 \mathrm{~A}}:$ Rab8a complexes to resolutions of $1.914 \AA$ and $2.0 \AA$, respectively, as described in materials and methods. The complex structures are quite similar, and we describe the bMERB $_{\text {M1116A }}:$ Rab8a structure in detail.

Two copies with an overall similar architecture of $\mathrm{bMERB}_{\mathrm{M} 1116 \mathrm{~A}}$ :Rab8a complex per asymmetric unit were observed (Supplementary Fig. 5a, b). Consistent with previously reported bMERB structures, the EHBP1 bMERB domain displays the same three helical-fold organization ${ }^{4,24}$ and helices $1-2$ of the bMERB $_{M 1116 \mathrm{~A}}$ domain have a slightly different conformation in both copies, indicating that this part is somewhat flexible (Supplementary Fig. 5b); however, the Rab8a binding site adopts the same conformation in both copies. The EHBP $1_{\text {bMERB }}$ domain shows an RMSD of $2.3 \AA$ for 122 residues to Mical $\mathrm{cL}_{\mathrm{bMERB}}$ (PDB 5SZI), RMSD of $2.5 \AA$ for 120 residues to Mical $3_{\text {bMERB }}$ (PDB 5SZG) and RMSD of $3.6 \AA$ for 119 residues to Mical $1_{\text {bMERB }}$ (PDB 5LPN), whereas Rab8a is quite similar to Rab8a/10 of Mical $\mathrm{cL}_{\mathrm{bMERB}}:$ Rab8a /Mical1 $1_{\mathrm{bMERB}}:$ Rab10 complex (RMSD $0.6 \AA$ ) (Supplementary Fig. 5c-e).

Similar to previously reported bMERB:Rab complex structures $^{4}$, the major interactions between Rab8a and bMERB ${ }^{\text {EHBP1 }}$ involve $a$-helix 3 , and some additional interaction surface is provided by residues from $\alpha$-helix 2 . Hydrophobic side chains of Rab8a switch I (I41 and I43) and switch II (F70, I73, and Y77) are buried in a hydrophobic core of the interface formed by a-helices 2-3 (Y1149, L1156, L1160, L1179, L1182, and V1183) (Fig. 6c, d). A conserved triad of aromatic amino acids (F45, W62, and Y77) also forms hydrophobic interactions with V1186 and L8, F45, and I47 of Rab8a interact with V1193 of the bMERB domain (Fig. 6b and Supplementary Fig. 5b). Besides these interactions, the interswitch region (F45, I47, Q60, and W62) and Rab subfamily motif1 (RabSF1, Y5, and L8) ${ }^{33}$ of Rab8 also interact with the bMERB ${ }^{E H B P 1}$ domain. Several polar interactions were observed between Rab8a and the bMERB domain, including between side chains of T4 Rab8a-E1200, Y5 Rab8a-D1197, D44 Rab8a-R1189, D44 Rab8a_Y1149, Q60Rab8a_D1190, R69Rab8a_-Q1176, Y77Rab8a_ N1187, and the F45 Rab8a backbone carbonyl forms a hydrogen bond with R1189 side chain (Fig. 6a-d). T72 Rab8a is not involved in any direct interaction with the bMERB domain, explaining why mutant T72E has no effect on bMERB ${ }^{\mathrm{EHBP} 1}$ binding (Supplementary Fig. 5b).

bMERB Ct-hydrophobic patch is crucial for Rab8 interaction. Previously, we have shown that the N-terminus of Rab8 family members provides specificity with respect to interaction with bMERB $^{4}$. Here, we sought to determine the contribution of essential bMERB residues that are necessary for Rab8 interaction. Similar to the $\mathrm{CH}$-binding site, a robust cluster of hydrophobic residues was observed in the bMERB:Rab-binding interface (Fig. 6a-d) and to test the importance of this hydrophobic patch, we mutated the leucine residues of bMERB to serine and valine to alanine (Fig. 6c, d). The L1156S mutation leads to a 47 -fold reduction in affinity (Fig. 6f); L1156 is part of the LR motif that is conserved in bMERB family members (Supplementary Fig. 3e). L1156 has only one close hydrophobic contact, with I41 of Rab8a. It nevertheless appears to be essential for maintaining the 

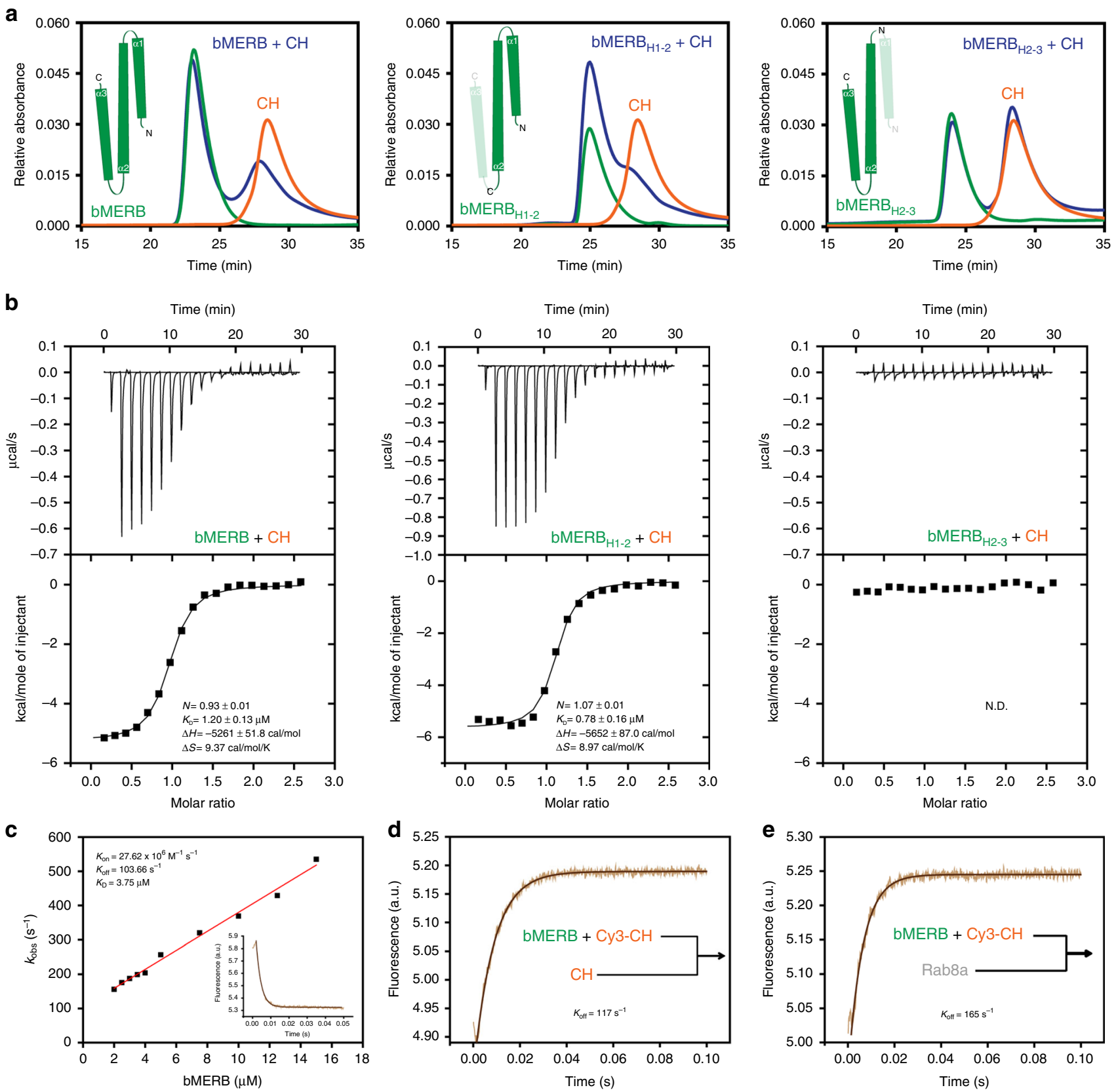

\begin{tabular}{llc}
\hline bMERB & & $K_{\mathrm{D}}(\mu \mathrm{M})$ \\
\hline Mical1 & $\mathrm{CH}$ & N.D. \\
Mical1 & $\mathrm{LIM}$ & N.D. \\
Mical1 & $\mathrm{CH}-\mathrm{LIM}$ & N.D. \\
Mical3 & $\mathrm{CH}$ & N.D. \\
Mical-L1 & $\mathrm{CH}$ & N.D. \\
EHBP1 & $\mathrm{CH}$ & 1.2 \\
\hline
\end{tabular}

integrity of the hydrophobic patch formed by helices 2 and 3 of the bMERB domain. The effect of L1160S on Rab binding was less pronounced, leading to a 2-3-fold reduction in binding affinity (Fig. 6g). However, mutations L1179S and L1182S led to a tenfold decrease in binding affinity (Fig. 6i-j). We could not detect binding in the case of the V1183A mutant that is involved in hydrophobic interactions with I43, I73, and Y77 (Fig. 6k). Altogether, our data suggest that the continuous C-terminal hydrophobic patch on bMERB is essential for the formation and stability of the Rab-binding site. Besides the hydrophobic patch residues, we also mutated several polar residues of the bMERB domain to alanine. Mutation of Q1176A does not have any effect (Fig. 6h). V1186A displays a more than 30 -fold reduction in binding affinity (Fig. 6l) and this residue forms hydrophobic interactions with a conserved triad of aromatic amino acids (F45, W62, and Y77). Mutation of N1187A and R1189A led to a 5 and 
Fig. 3 Interaction between the CH and the bMERB domain of EHBP1 and disruption by Rab8. a The bMERB domain (green), CH domain (orange), and a mixture of both (blue) were loaded onto a Superdex 75 10/300 GL column to monitor for complex formation. Clear complex formation was observed for the construct lacking the $\mathrm{C}$-terminal helix (indicated as green helices in the insets). However, in the case of the full-length construct, only a shift in the $\mathrm{CH}$ domain peak was observed, indicating distribution between free and EHBP1 bMERB bound CH domain at the concentrations used. No complex formation or shift in the $\mathrm{CH}$ peak was observed for the construct lacking the $\mathrm{N}$-terminal helix. $\mathbf{b}$ Binding affinities were measured by titrating the $\mathrm{CH}$ domain (800 $\mu \mathrm{M}$ ) to either the full length or N/C-terminally truncated bMERB domain $(60 \mu \mathrm{M})$. Integrated heat peaks were fitted to a one-site-binding model yielding the binding stoichiometry $(N)$, the enthalpy $(\Delta \mathrm{H})$, the entropy $(\Delta S)$, and the dissociation constant $\left(K_{D}\right)$. The data are representative of at least three repetitions. c Observed association first-order rate constants between $0.5 \mu \mathrm{M}$ Cy3 labeled $\mathrm{CH}$ domain with different concentrations of full-length bMERB domain $(2-16 \mu \mathrm{M})$. Kinetics were registered as a change in fluorescence using a stopped-flow apparatus at $25^{\circ} \mathrm{C}$. Association of bMERB to the $\mathrm{Cy3}-\mathrm{CH}$ leads to a decrease in the fluorescence. As an example, the kinetics of association between $0.5 \mu \mathrm{M}$ Cy3 labeled $\mathrm{CH}$ domain and $5 \mu \mathrm{M}$ of bMERB domain is shown in the inset. $\mathbf{d}$, e Dissociation of the $\mathrm{CH}$ domain was measured by monitoring the increase of fluorescence after mixing a complex of $\mathrm{Cy} 3$ labeled $\mathrm{CH}$ with full-length bMERB domain $(2 \mu \mathrm{M})$ with a 20 -fold excess of either unlabeled $\mathrm{CH}$ domain or GppNHp Rab8a. $\mathbf{f}$ Results of systematic analysis of interactions between the bMERB domains of different family members with their respective $\mathrm{CH} / \mathrm{LIM} / \mathrm{CH}$-LIM domains (from Supplementary Fig. 2). Interactions were measured by ITC. N.D. denotes not detected.

a 20 -fold reduction in binding affinity, respectively (Fig. $6 \mathrm{~m}, \mathrm{n}$ ). $\mathrm{R} 1189$ is conserved throughout the bMERB family members (Supplementary Fig. 5e). Taken together, our data suggest that the C-terminal hydrophobic patch is crucial for the Rab interaction, and the conserved arginine residue R1189 also contributes significantly to the binding affinity.

In line with the ITC results, bMERB constructs having low Rab8a binding affinity failed to form stable complexes in gel filtration experiments (Supplementary Fig. 7).

Structural basis of $\mathrm{CH}$ domain release upon Rab8 binding. To unravel the structural basis for the release of the $\mathrm{CH}$ domain from the bMERB domain upon Rab8 binding, we superimposed the $\mathrm{bMERBH}_{1-2}: \mathrm{CH}$ complex structure with that of $\mathrm{bMERB}_{\mathrm{M} 1116 \mathrm{~A}}$ : Rab8a (Fig. 7a). The first two helices of the bMERB domain adopt the same conformation in both structures, while the third helix of the bMERB domain in the presence of Rab8 adopts a defined conformation which would infringe spatially on the $\mathrm{CH}$ domain binding site, suggesting that the CH:bMERB:Rab8 triple complex could not be formed because of a steric clash (Fig. 7a and Supplementary Fig. 8a). This finding complements our transient kinetic data showing that the binding of Rab8a to the bMERB domain releases the $\mathrm{CH}$ domain. The structures also suggest that in the absence of Rab8a, helix 3 of bMERB domain must adopt a different conformation, or be flexible, so that the full-length bMERB domain can form a stable complex with the $\mathrm{CH}$ domain.

To compare the Rab-and $\mathrm{CH}$-binding sites on the bMERB domain, we have cut the second helix in the middle and aligned the resulting two hairpins (Fig. 7b). This alignment shows that the two halves of the bMERB domain are quite similar, a characteristic feature of bMERB family members indicating that bMERB domains are evolved by gene duplication of this helical hairpin $^{4,5}$. The sequence alignment shows that the residues that are involved in $\mathrm{CH}$ and Rab binding are quite similar and mutation of some of these residues led to similar effects (Fig. 7c).

Further, to understand the biological significance of $\mathrm{CH}$ domain release and to identify the probable F-actin binding site in the $\mathrm{CH}$ domain, we have utilized the filamin A ABD_E254K:Factin (PDB 6D8C, $3.6 \AA$ ) cryo-EM structure ${ }^{34}$. A superposition of the $\mathrm{CH} 1^{\mathrm{FLNa}}$ and $\mathrm{CH}^{\mathrm{EHBP} 1}$ domains indicates a similar structure (RMSD of $2.5 \AA$, 99 aligned Cas) (Fig. $7 \mathrm{~d}$ and Supplementary Fig. $8 \mathrm{~b}-\mathrm{d}$ ). To understand the binding mode, the $\mathrm{CH}^{\mathrm{EHBP} 1}$ domain was superimposed onto the $\mathrm{CH} 1^{\mathrm{FLNa}}$ domain. To optimize the contacts to the actin filament and to obtain the best fit to the $\mathrm{CH}$-binding pocket, the $\mathrm{CH}^{\mathrm{EHBP} 1}$ model was manually adjusted to relieve minor clashes, mainly by shifting the short helix 522-529 (residues PSDMVLLA) and the following loop, and then energy minimized with Macromodel (Schrodinger suite $^{35}$ ) and PHENIX ${ }^{36}$. It is clear that the main contact site of the
$\mathrm{CH}^{\mathrm{EHBP} 1}$ domain that corresponds to ABS2 is occupied by bMERB in the CH:bMERB complex structure, indicating that the bMERB domain has to dissociate to facilitate F-actin binding of the $\mathrm{CH}$ domain. The optimized $\mathrm{CH}^{\mathrm{EHBP}}$ :F-actin model has a smaller buried interaction interface area $\left(4640 \AA^{2}\right)$ between the $\mathrm{CH}$ domain and F-actin compared with the $\mathrm{CH}_{1}{ }^{\mathrm{FLNa}}$ :F-actin $\left(6000 \AA^{2}\right.$ ) (Fig. 7e). This is mainly due to missing ABS-N and a smaller ABS2' in the $\mathrm{CH}^{\mathrm{EHBP} 1}$ domain (Fig. $7 \mathrm{~d}$ and Supplementary Fig. 7c). Since the $\mathrm{CH}^{\mathrm{EHBP} 1}$ domain has lower affinity to $\mathrm{F}$ actin compared with filamin A, the smaller buried interface could indeed correspond to the physiological situation. However, we cannot rule out the possibility of different or more extensive Factin induced conformational changes in the $\mathrm{CH}^{\mathrm{EHBP} 1}$ domain upon binding. Further structural studies are required to understand the F-actin: $\mathrm{CH}^{\mathrm{EHBP} 1}$ interaction. However, our model suggests that for F-actin association, the $\mathrm{CH}^{\mathrm{EHBP} 1}$ domain has to be free, i.e., not bound to the bMERB domain.

\section{Discussion}

EHBP1 has a central role in vesicular trafficking and lipophagy, yet its regulation is not understood. This work offers mechanistic insight into the EHBP1 activation mechanism by Rab8 family members. We have shown that both $\mathrm{N}$-and C-termini of EHBP1 have the potential to interact with the membrane; the NT-C2 domain binds to $\mathrm{PI}(3) \mathrm{P}, \mathrm{PI}(5) \mathrm{P}$, and phosphatidylserine, lipid molecules present in the early endosomes and plasma membrane respectively. Previously, we reported that the EHBP1 CaaX box can be farnesylated ${ }^{4}$. The presence of two membrane-associating moieties can fine-tune the EHBP1 function by regulating its localization.

We have found that unlike Mical1, EHBP1 has only a single highly conserved C-terminal high affinity Rab-binding site and the so-called low-affinity binding site can be occupied by the $\mathrm{CH}$ domain. In the absence of Rab8, EHBP1 exists in a closed form with the C-terminal bMERB domain interacting with the central $\mathrm{CH}$ domain so that its binding with actin filaments is perturbed. Several previous studies indicated that an intramolecular interaction occurs between the bMERB domain with the various other domains (CH/LIM/MO-CH-LIM), and were suggested to be inhibitory ${ }^{21-24}$. Fremont et al., proposed a model for Micall activation in which an intramolecular association occurs between the C-terminal bMERB domain and the N-terminal mono-oxygenase together with the $\mathrm{CH}$ and LIM domains (MO-CH-LIM), forming an enzymatically dead complex. Binding of Rab35 can release the auto-inhibition, resulting in increased F-actin depolymerization ${ }^{19,20}$. Mical-like family members also engage in intramolecular interaction between their N-terminal $\mathrm{CH}$ domain (Mical-L1) or LIM domain (Mical-L2) with their C-terminal bMERB domain ${ }^{21,23}$. The present work is the first to perform 
a

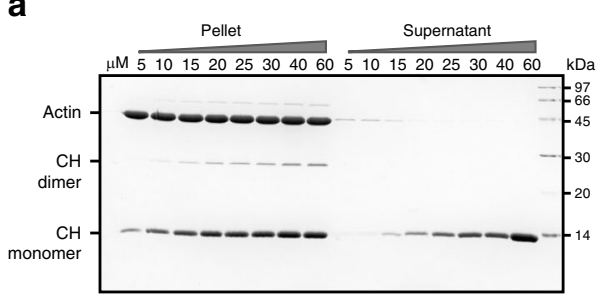

b

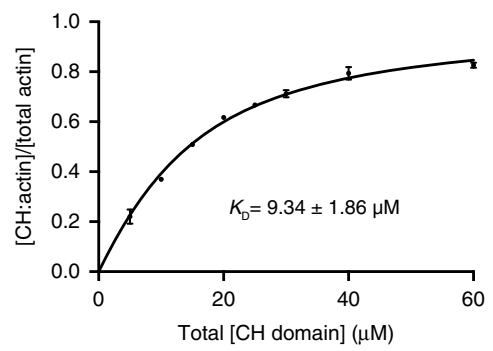

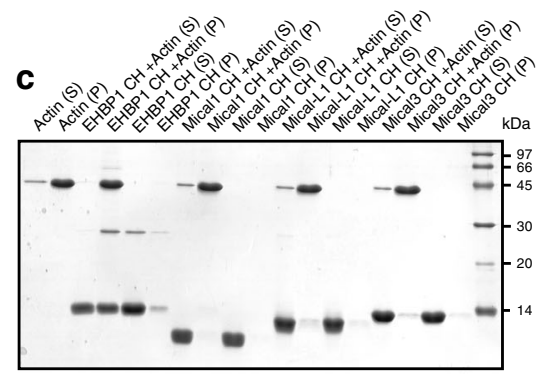

e

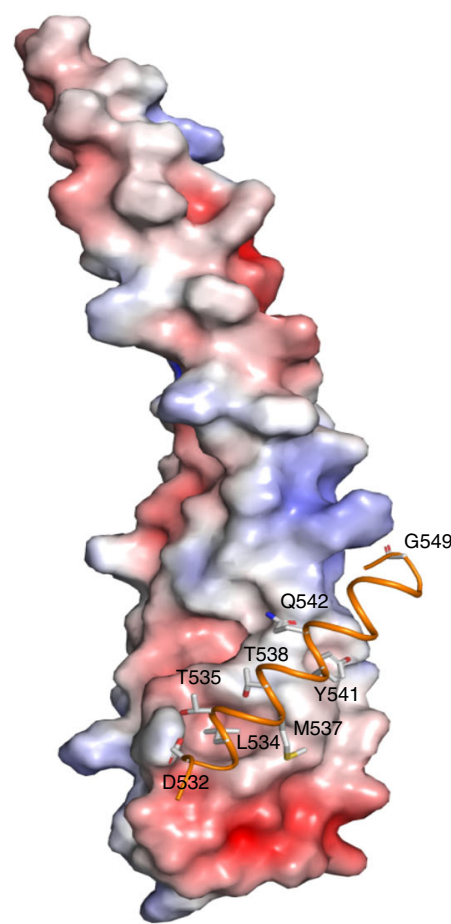

d

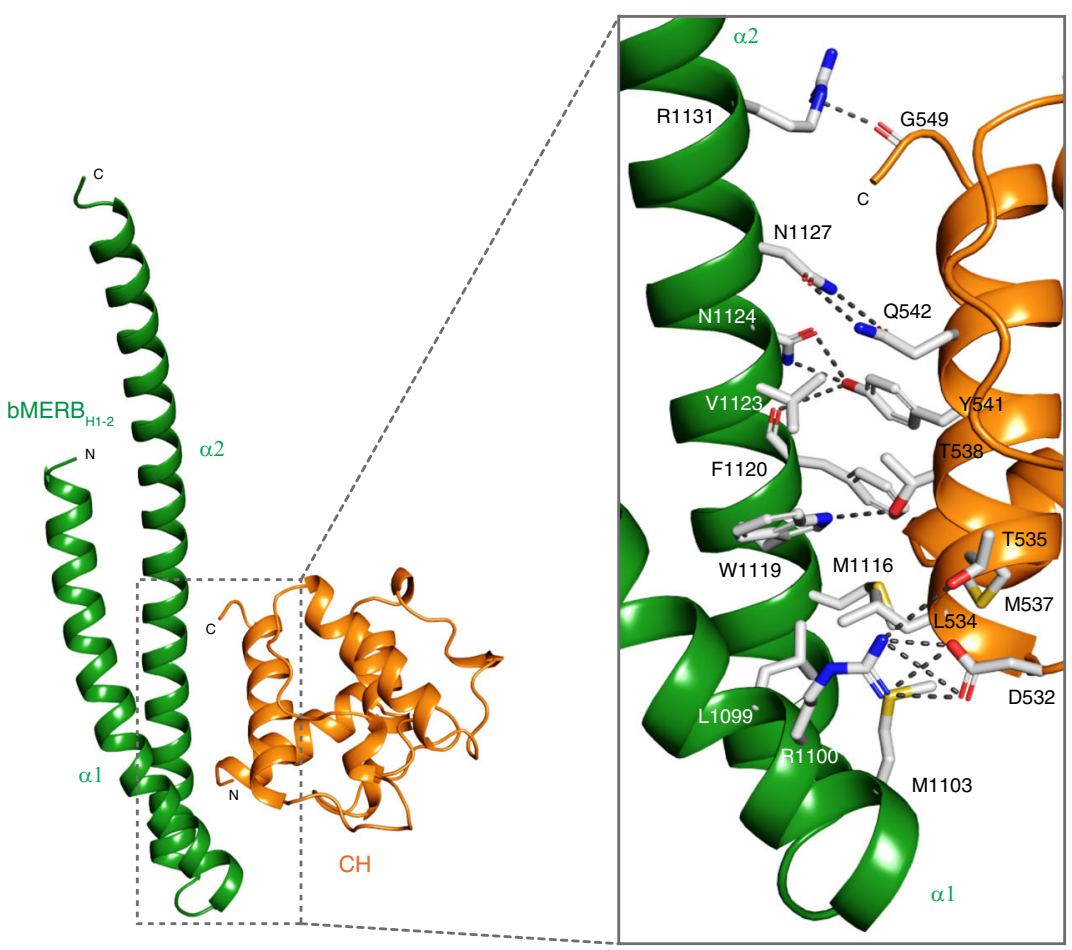

f

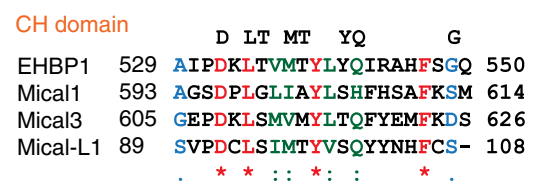

bMERB domain

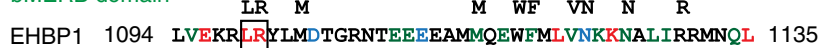

Mical1 951 KLELA RRRQSSSP--EQQKKLWVGQLLQLVDKKNSLVAEEAEL 991

Mical3 1874 AVEKALR GEAGMG--KKDDPKLMQEWFKLVQEKNAMVRYESEL 1914

Mical-L1 704 LLEEK ER GGLNEG--REDD--MLVDWFKLIHEKHLLVRRESEL 742

Fig. 4 CH domain interaction with F-actin and structure of the EHBP1 $\mathbf{C H}: \mathbf{b} \mathbf{M E R B}_{\mathbf{H 1}-\mathbf{2}}$ complex. a The EHBP1 $\mathrm{CH}$ domain co-sediments with F-actin filaments in vitro. SDS-PAGE of pellets and supernatants from high-speed centrifugation performed at a fixed concentration of $\mathrm{F}$-actin (10 $\mu \mathrm{M})$ and with varying concentrations of the EHBP1 CH domain $(0-60 \mu \mathrm{M})$ is shown. $\mathbf{b}$ The normalized fraction of F-actin bound EHBP1 $\mathrm{CH}$ domain as a function of total EHBP1 CH domain concentration. Values were calculated from densitometry of SDS-PAGE. The data from two technical repeats are shown as means \pm s.d. $(n=2)$. The error bars are included in the plot but are too small to be displayed on several of the points. c Results of systematic analysis of interactions between the $\mathrm{CH}$ domains of different bMERB family members with $\mathrm{F}$-actin via co-sedimentation experiments. Only the EHBP1 CH domain interacts with Factin. Experiments were repeated at least two times independently with similar results. Source data are provided as a Source Data file. $\mathbf{d}$ Cartoon representation of the $\mathrm{CH}: \mathrm{bMERB}_{\mathrm{H} 1-2}$ complex structure. The bMERB domain is colored green and the $\mathrm{CH}$ domain in orange. The inset shows the zoom-in overview of the $\mathrm{CH}: \mathrm{bMERB}$ interaction interface. Hydrogen bonds and polar interactions are shown in gray dashed lines. e Surface electrostatic potential of bMERB $_{\mathrm{H} 1-2}$ calculated in PyMOL using the APBS-PDB2PQR plugin and visualized in red to blue $(-5 \mathrm{kT} / \mathrm{e}$ to $+5 \mathrm{kT} / \mathrm{e})$. The $\mathrm{C}$-terminal helix of the $\mathrm{CH}$ domain is shown. $\mathbf{f}$ Sequence alignment of the interacting regions of the $\mathrm{CH}$ and the bMERB domain of different bMERB family members. Residues directly involved in the $\mathrm{CH}$ :bMERB interactions are shown over the top of sequence alignment and the conserved LR motif is shown in the black box.

biochemical characterization of the auto-inhibited bMERB complexes, but, we could not detect any interaction between the bMERB domain of Mical family members with their respective CH/LIM/CH-LIM domain (Supplementary Fig. 2), although this could be due to a weaker affinity, which is high enough to lead to an intramolecular interaction, but not enough to be detected in the intermolecular situation. Further experiments with longer constructs are required.

Here, we report the CH:bMERB and bMERB:Rab8 complex structures and demonstrate that the integrity of both $\mathrm{N}$-and Cterminal hydrophobic patches is crucial for the $\mathrm{CH}$ and $\mathrm{Rab}$ interactions. We show that the $\mathrm{CH}$ and Rab-binding sites of the 
a

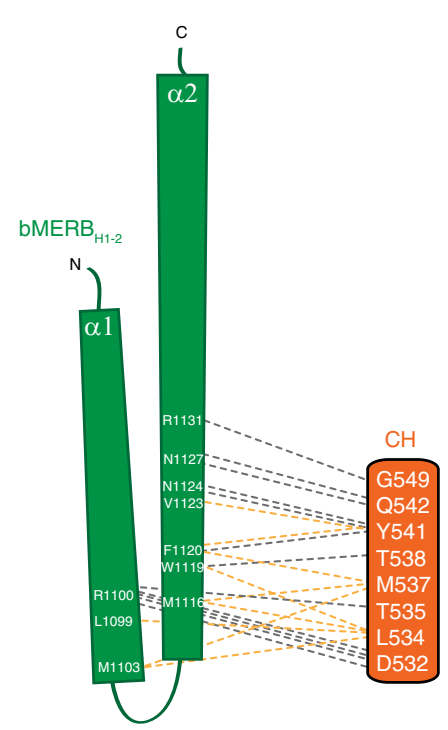

b

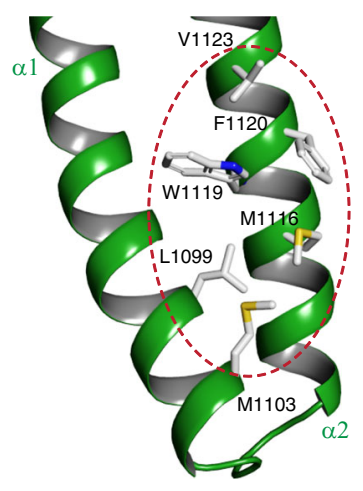

Hydrophobic patch
C
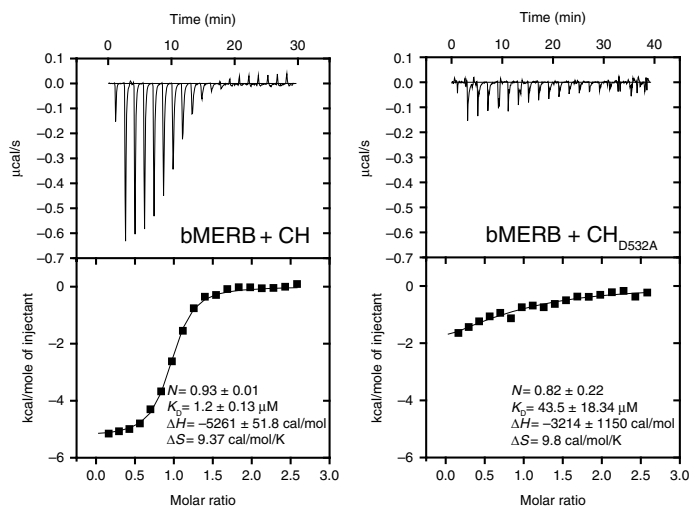

d

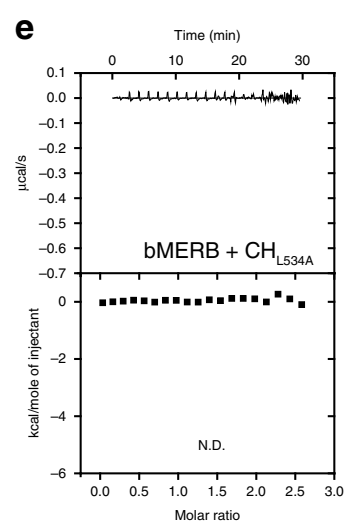

f
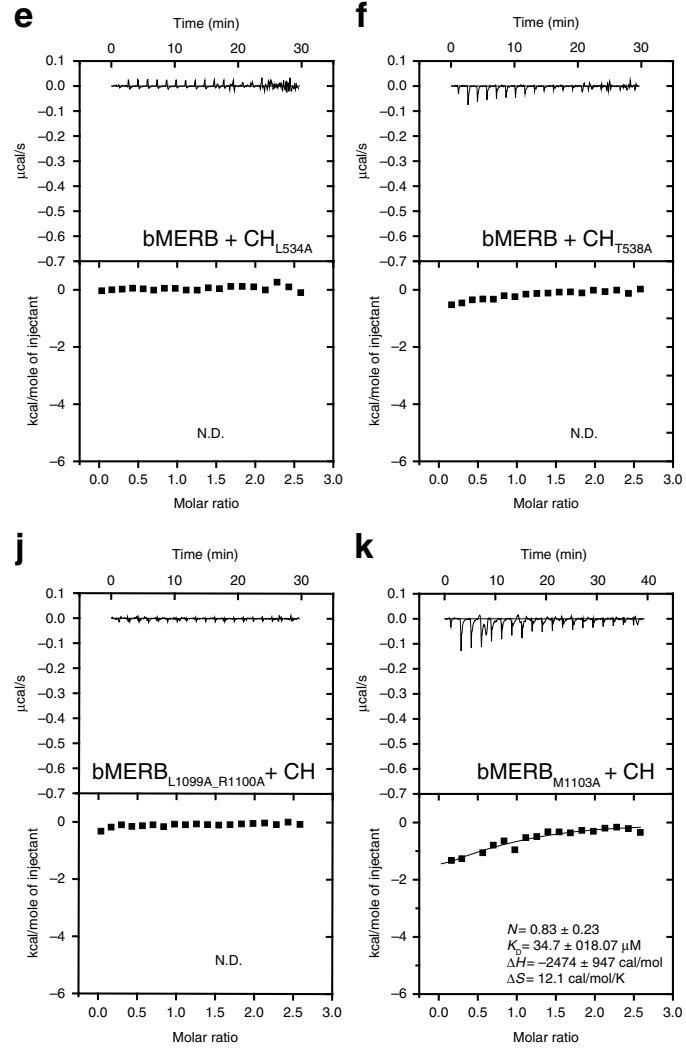

$\mathbf{k}$
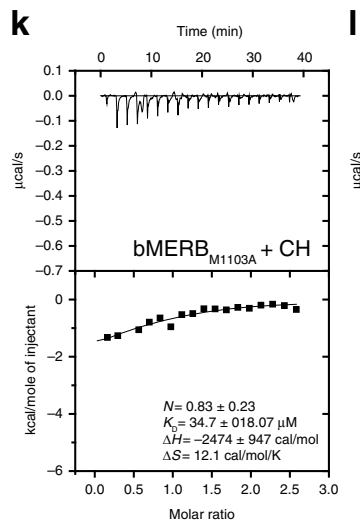

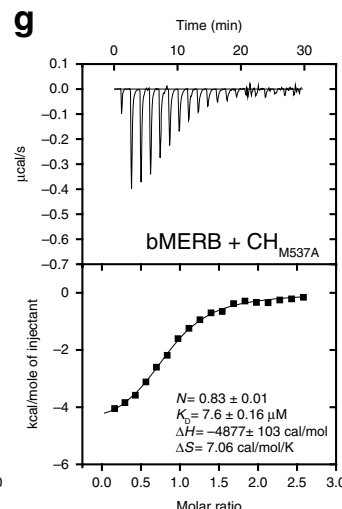

h
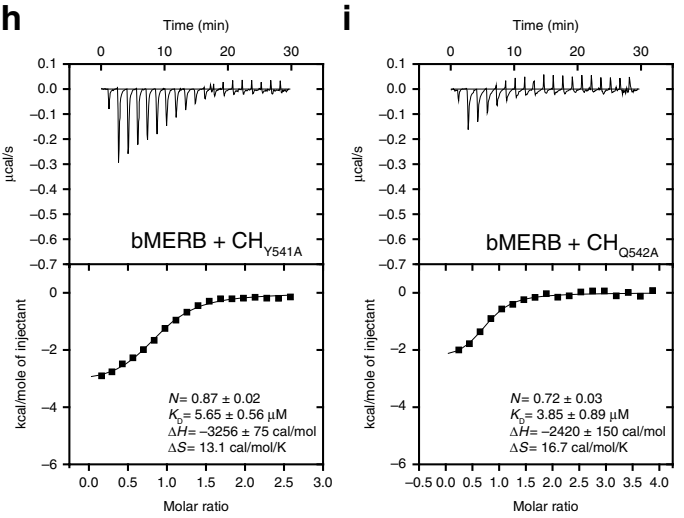

$\mathbf{m}$

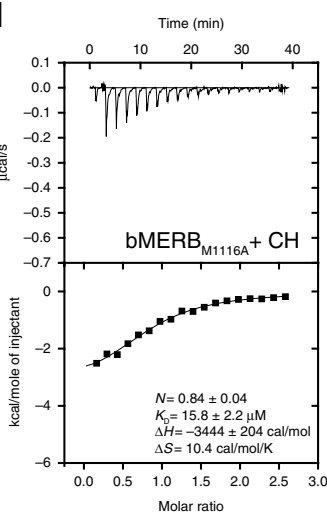

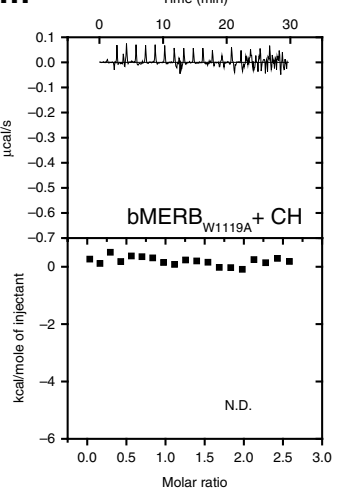

Fig. 5 The $\mathbf{N}$-terminal hydrophobic patch of bMERB domain is essential for the $\mathbf{C H}$ domain interaction. a Schematic illustration of the interactions between the $\mathrm{bMERB}_{\mathrm{H} 1-2}$ domain and the $\mathrm{CH}$ domain $\mathrm{C}$-terminal helix. Hydrophobic interactions are indicated by light orange dashed lines, ionic interactions, and $\mathrm{H}$-bonds are indicated by gray dashed lines. $\mathbf{b}$ Hydrophobic residues at the $\mathrm{CH}$-binding site of the EHBP1 bMERB domain. c-n Mutational alanine screening of the $\mathrm{CH}: \mathrm{bMERB}$ complex binding interface via ITC measurements. Mutation of the $\mathrm{CH}$ domain residues that are involved in stabilization of the hydrophobic patch results in a significant defect in binding and the integrity of the hydrophobic patch is crucial for the $\mathrm{CH}$ interaction. The data are representative of at least three repetitions. N.D. denotes not detected.

bMERB domain have significant similarities (e.g., the conserved LR motif of helix $1^{\mathrm{CH}}$ _bs and helix $2^{\mathrm{Rab}}$ bs is essential for $\mathrm{CH} /$ Rab8 interaction and similarly $\mathrm{CH}$ and $\mathrm{Rab}$ aligned interacting residues M1116/L1179, W1119/L1182, and F1120/V1183 are for the $\mathrm{CH} / \mathrm{Rab}$ interaction). Small changes in the amino acid sequence of the two halves determine the specificity toward $\mathrm{CH}$ or Rab binding.
Structural alignment of the EHBP $1_{\mathrm{bMERB}}$ :Rab8 complex with other published structures shows that the C-terminal high affinity Rab-binding site is quite conserved in all structures (Supplementary Fig. 5c-e). However, the conformation of helix 1 and helix 2 differs at the $\mathrm{CH} /{ }^{2 n d}$ Rab-binding site. Further, superposition of the Mical $1_{\mathrm{bMERB}}:$ Rab10 (1:2) complex with EHBP $1_{\text {bMERB_M1116A }}:$ Rab8a shows that the conformation of 

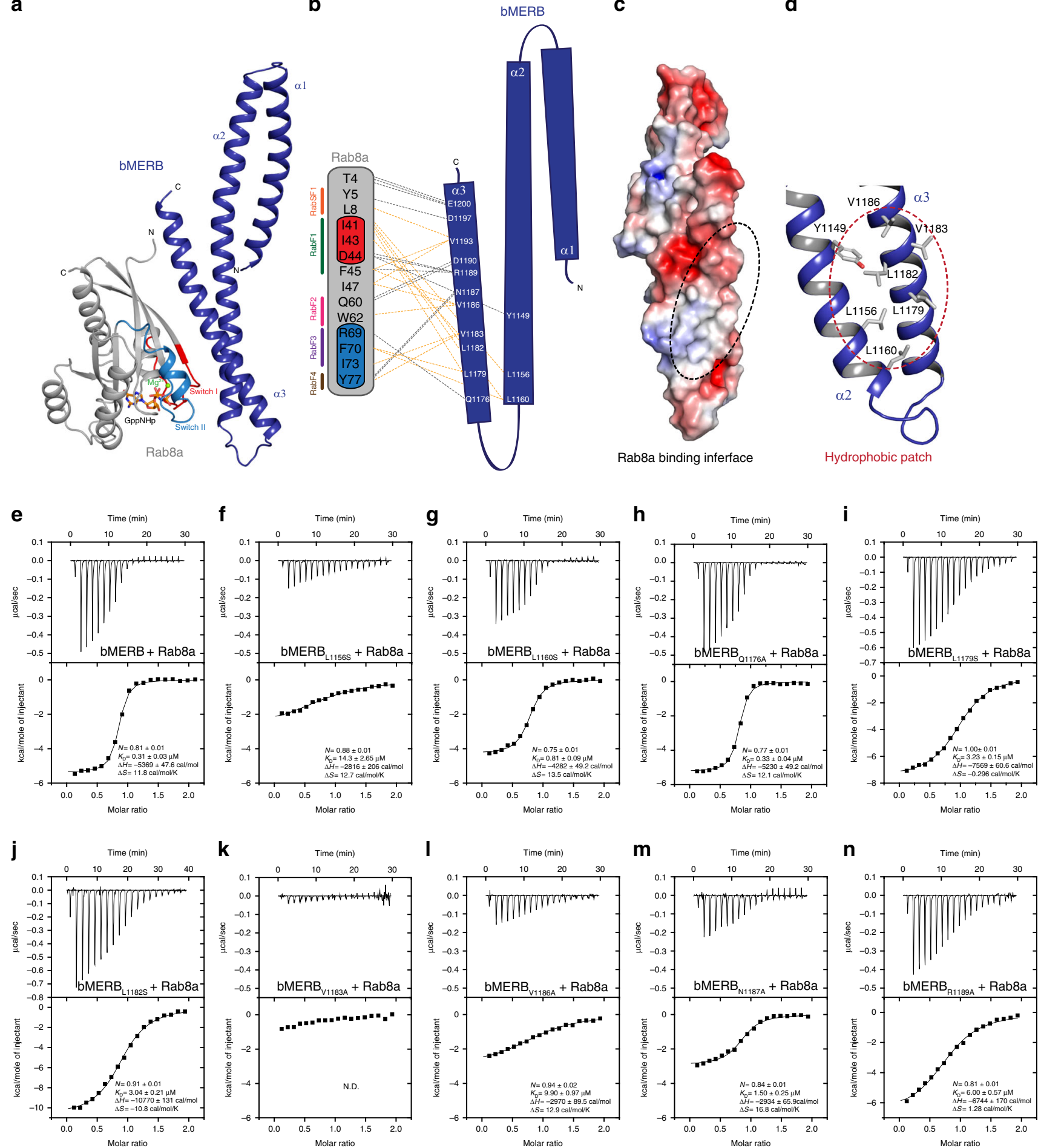

Fig. 6 The C-terminal hydrophobic patch of the bMERB domain is crucial for Rab8a interaction. a Cartoon depiction of the EHBP1 bMERB ${ }_{M 1116 A:}$ Rab8a $a_{\text {Gp NHp }}$ complex. Rab8a $a_{\text {GpNHp }}$ (gray, chain B) binds to EHBP1 bMERB (blue, chain D) via its N-terminal regions, the switch regions as well as the inter-switch region. Switch I and switch II are shown in red and blue, respectively. GppNHp and $\mathrm{Mg}^{2+}$ are depicted as sticks and a green sphere,

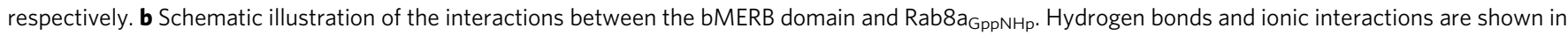
gray dashed lines and light orange dashed lines indicate hydrophobic interactions. RabSF1, RabF1, RabF2, RabF3, and RabF4 motifs are shown in orange, green, pink, purple, and brown respectively. c Electrostatic potential of the bMERB domain calculated in PyMOL using the APBS-PDB2PQR plugin and visualized in red to blue $(-5 \mathrm{kT} / \mathrm{e}$ to $+5 \mathrm{kT} / \mathrm{e})$. The dashed line highlights the region that interacts with Rab8a. $\mathbf{d}$ The $\mathrm{C}$-terminal hydrophobic patch of the EHBP1 bMERB domain. e-n Mutational characterization of the bMERB:Rab8a complex interface. Binding of GppNHp Rab8a $a_{1-176}$ with different EHBP1 bMERB mutants was systematically tested and affinities were measured by ITC experiments. The data are representative of at least three repetitions. N.D. denotes not detected. 
a

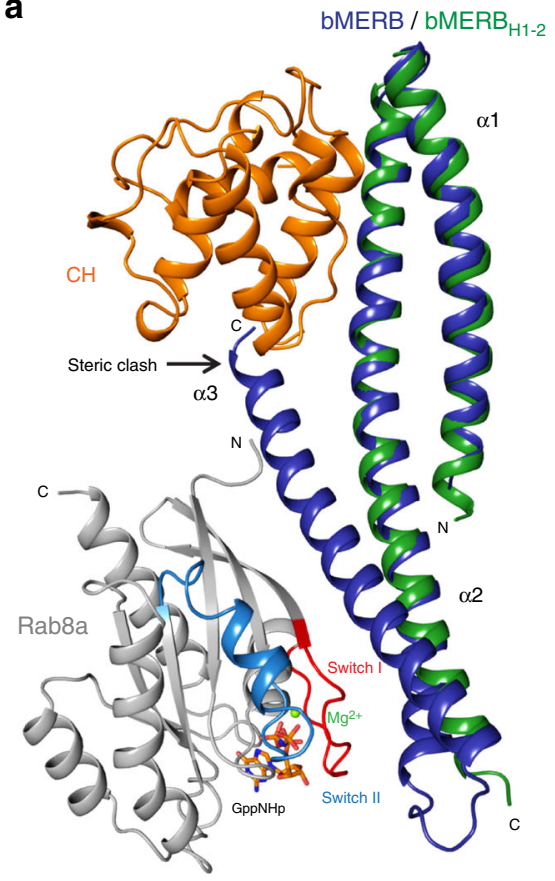

b

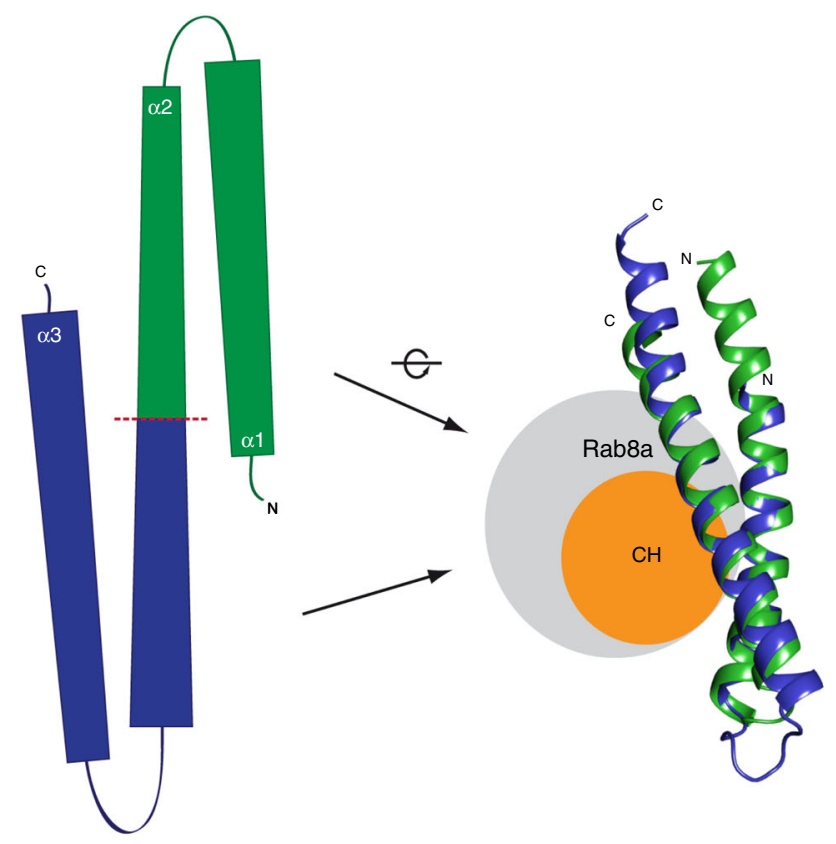

c

$\alpha 1$

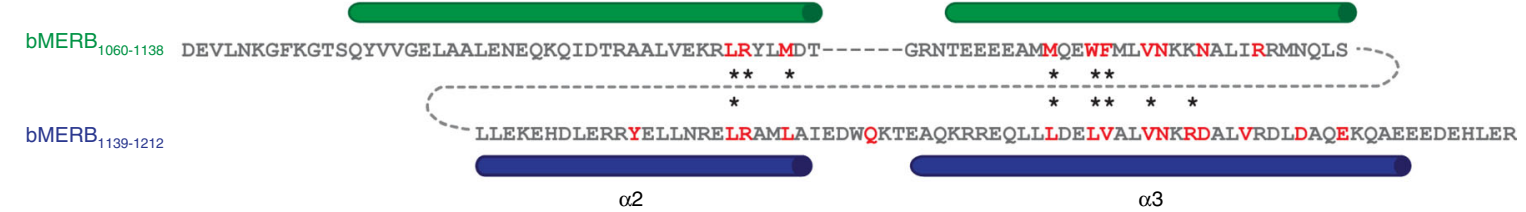

d

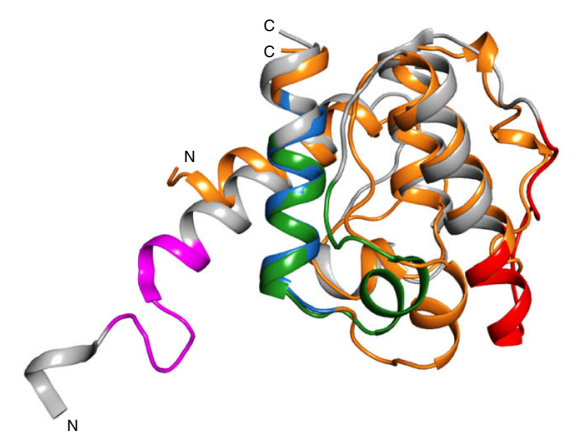

EHBP1_CH / bMERB_BS

Filamin A_CH1 / ABS-N / ABS 2' / ABS2 PDB: 6D8C; RMSD $2.5 \AA$ A (C $\alpha-99)$ e

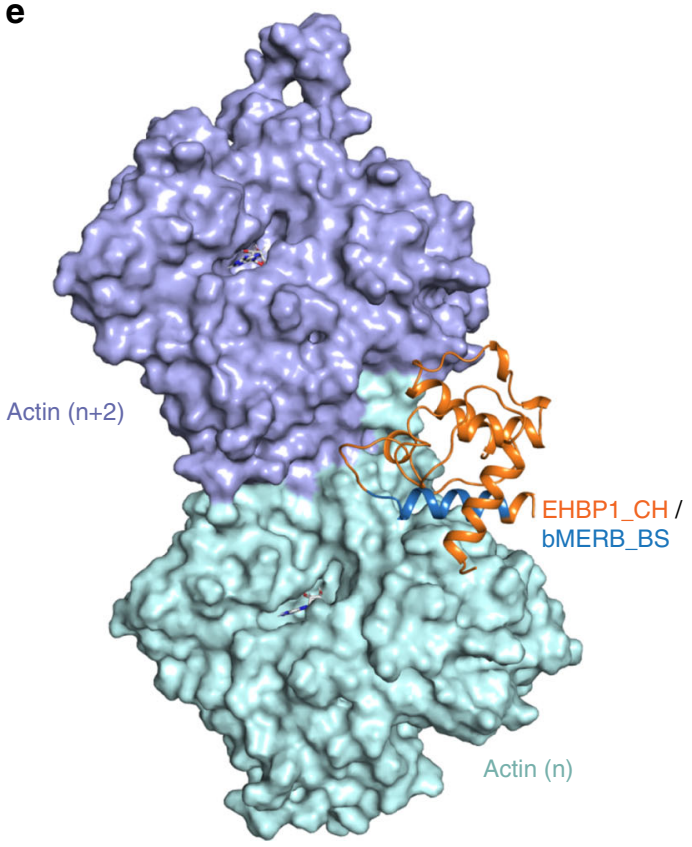

ability to be targeted to the membrane, and Rab8 only binds to the highly conserved C-terminal Rab-binding site of the bMERB domain, changing helix 3 conformation, and leading to release of auto-inhibition.

In agreement with recent work on Mical1 ${ }^{37}$, we show that phosphomimetic mutation of the switch II threonine of Rab8/10 does not affect its interaction with the $\mathrm{EHBP} 1_{\mathrm{bMERB}}$ domain and 
Fig. 7 Structural basis of the $\mathbf{C H}$ domain release from the bMERB domain upon Rab8a binding. a Structural superposition of the EHBP1 $b M E R B_{\mathrm{H} 1-2}: \mathrm{CH}$

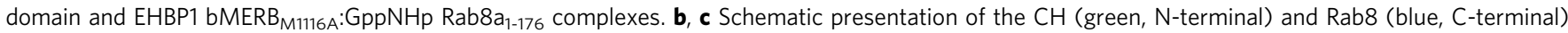
binding site of EHBP1 bMERB domain. Structural and sequence alignment of the $\mathrm{N}$-and $\mathrm{C}$-terminal halves of the EHBP1 bMERB domain, showing strong conservation between both $\mathrm{CH}$ and Rab8a binding sites. $\mathrm{CH}$ and Rab8a interacting residues are shown in red. ${ }^{*}$ denotes critical residues for the interaction. d Structural alignment of the EHBP1 CH domain (orange, bMERB binding site (bMERB_BS) in blue) with the filamin A CH1 domain (gray). F-actin binding sites in the filamin $A C H 1$ domain are shown in pink ( $A B S-N)$, red (ABS2'), and in green (ABS2). (ABS actin binding site). e Structural model of the F-actin: EHBP1 CH domain complex, based on the complex structure of filamin A CH1 domain:F-actin (PDB ID 6D8C). The bMERB binding site (bMERB_BS, blue) of the $\mathrm{CH}$ domain is buried by the actin filament.

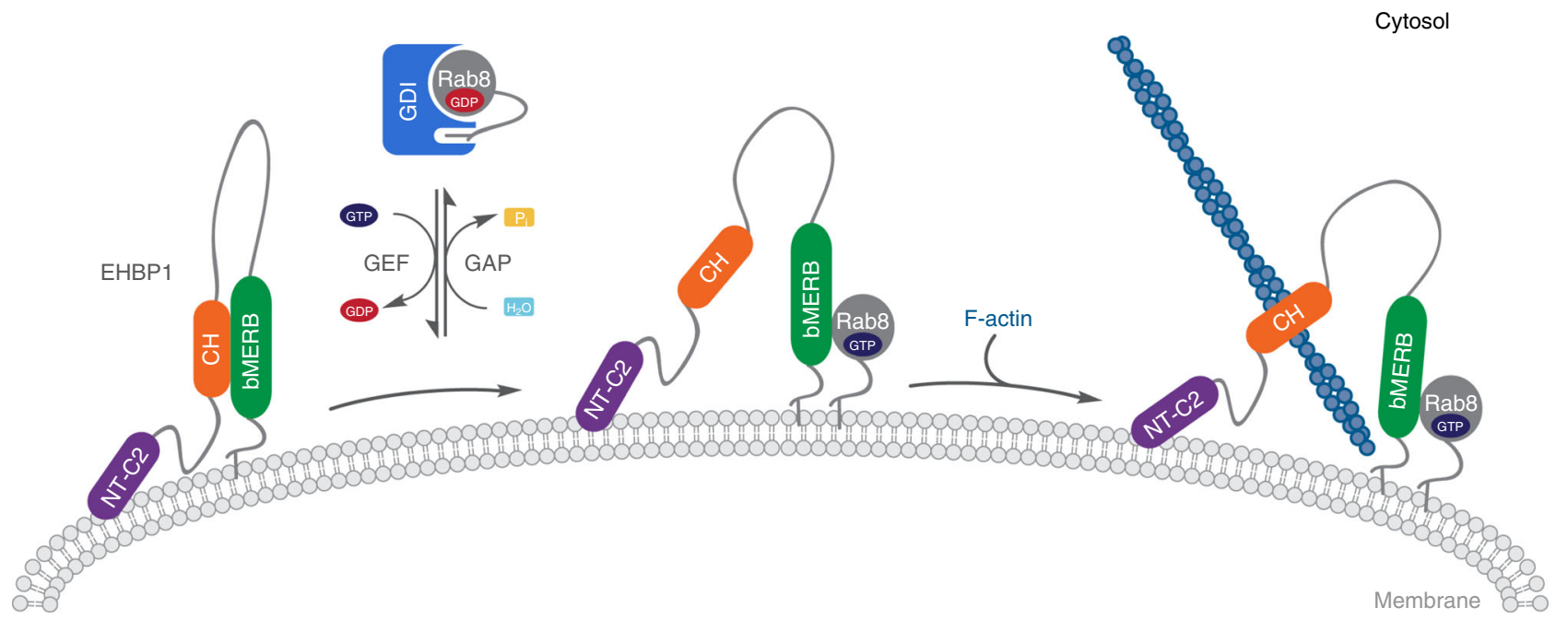

Fig. 8 Mechanistic model of the EHBP1 activation by Rab8 family members. In the absence of active Rab8, EHBP1 exists in a closed conformation in which the $\mathrm{CH}$ domain interacts with its bMERB domain. Rab8 is recruited to the membrane by its GEF molecule (e.g., Rabin 8 or GRAB) and the resulting active GTP bound Rab8 interacts with the EHBP1 bMERB domain; this interaction makes the CH domain available for F-actin interaction.

is not part of the bMERB binding interface (Supplementary Fig. 5b). In contrast, a study of the RILPL2:Rab8 interaction has shown that phosphorylation of switch II T72 is essential for the interaction and also stabilizes the RILPL2:Rab8 complex (PDB 6RIR $)^{38}$, suggesting that the phosphorylation of switch II threonine has a selective effect on different effector molecule interactions.

In the last part of the work, we have shown that unlike a conventional F-actin binding domain, which requires an open conformation $\mathrm{CH} 1-\mathrm{CH} 2$ structure, the $\mathrm{CH}^{\mathrm{EHBP} 1}$ ( $\mathrm{CH} 2$-type) domain binds to F-actin ${ }^{25,26}$. Previously, it was shown that the $C$. elegans $\mathrm{CH}^{\mathrm{EHBP1}}$ domain directly interacts with F-actin, and the authors suggested that Rab10 binding to the bMERB domain enhances the $\mathrm{CH}$ domain:F-actin interaction ${ }^{7}$. However, no difference was detected in the F-actin binding of the free $\mathrm{CH}$ domain versus a CH-bMERB fusion construct ${ }^{7}$. The authors did not consider an auto-inhibition model; instead, they proposed a model where Rab10 binding leads to multimerization of EHBP1, leading to a side by side placement of $\mathrm{CH}$ domains from the dimeric EHBP1, but no experimental proof is provided. Recently, Miyake et al. have reported a closed conformation mouse MicalL1 (LIM:bMERB) and binding of Rab13 opens up the Mical-L1, allowing its interaction with F-actin ${ }^{23}$. By homology modeling, the authors built the LIM:bMERB:Rab13 tripartite complex and also docked the LIM domain onto F-actin and suggested that for the F-actin interaction, the LIM domain has to be free. However, this model could not explain how Rab13 binding to the bMERB domain releases the LIM domain. They suggested that a second competitive Rab13 binding at the $\mathrm{N}$-terminal binding site is a prerequisite for the LIM:F-actin interaction. No stoichiometry is reported for the Mical-L1 $1_{\mathrm{bMERB}}$ :Rab13 complex, and appropriate biochemical and structural studies would be needed to characterize the bMERB:Rab13 and LIM:bMERB complexes. In the current study, we clearly showed that the binding of Rab8 to bMERB releases the $\mathrm{CH}$ domain and further, our $\mathrm{CH}$ :F-actin model suggests that for $\mathrm{F}$-actin interaction, the $\mathrm{CH}$ domain has to be free, since the bMERB-binding site is also part of the F-actin binding site (Fig. 8).

\section{Methods}

Plasmid cloning. Prokaryotic and eukaryotic expression constructs were generated by standard cloning techniques, using Phusion polymerase, restriction digestion, and ligation by T4 DNA ligase. Point mutants were generated by quick-change sitedirected mutagenesis, using Phusion polymerase. A detailed overview of all expression vectors employed in this study is presented in Supplementary Table 2. Primers used for plasmid cloning are listed in Supplementary Table 3. All plasmids were verified by DNA sequencing.

Fluorescence microscopy. The full length human mCherry-tagged Rab constructs $\left(\mathrm{Rab} \mathrm{a}_{\mathrm{Q} 67 \mathrm{~L}}, \mathrm{Rab} 10_{\mathrm{Q} 68 \mathrm{~L}}\right)$ used in this paper were described previously ${ }^{4}$. Full-length human $\mathrm{EHBP} 1_{\text {isofrom3 } 3}, \triangle \mathrm{NT}-\mathrm{C} 2-\mathrm{EHBP} 1_{\text {isofrom } 3}$, and $\mathrm{EHBP} 1_{\text {isofrom } 3} \Delta \mathrm{CaaX}$ constructs were cloned into the pEGFP $(\mathrm{C} 1)$ vector between XhoI and SmaI sites by conventional PCR using Human EHBP1 cDNA (Isoform 3, Dharmacon). The NTC2 domain was cloned into the pEGFP (N1) vector between XhoI and SmaI sites and all constructs were verified by DNA sequencing. Cos7 cells (ATCC: CRL-1651) were maintained in DMEM medium supplemented with $10 \%$ fetal bovine serum, $2 \mathrm{mM}$ L-glutamine, and penicillin/streptomycin at $37^{\circ} \mathrm{C}$ in the presence of $5 \%$ $\mathrm{CO}_{2}$. Cells were grown on a coverslip in 6-well plates until they reached $60-70 \%$ confluency and transiently transfected using linear polyethylenimine, MW 25000 (PEI, Polysciences Inc, 3:1 PEI:DNA (12:4 $\mu \mathrm{g})$. Expression was checked 16-24 h post transfection. Cells were fixed with $3.7 \%$ paraformaldehyde in PBS for $15 \mathrm{~min}$ at room temperature. After washing with PBS, coverslips were mounted on glass slides with SlowFade Gold antifade reagent (Invitrogen). For EHBP1 constructs, single-plane images were taken by an EVOS fl fluorescence microscope equipped with $60 \mathrm{x} / 1.42$ Plan-Apochromat oil immersion objective.

EHBP1:Rab co-localization images were taken with a Zeiss LSM800 confocal microscope equipped with a Plan-Apochromat 63x/1.4 Oil DIC M27 oil immersion objective. $3 \mathrm{D}$ stacks of $0.37 \mu \mathrm{m}$ steps were acquired and images from all focal 
planes were rendered as a single maximum-intensity projection image using ImageJ software and later assembled with Adobe Illustrator.

Lipid overlay assay. To assess the lipid-binding properties of the EHBP1 NT-C2 domain, we performed a protein-lipid overlay assay with recombinant His6-MBP (MBP: maltose binding protein)-NT-C2 domain fusion protein and His6-MBP was used as a control. $1 \mathrm{ng}$ of His6-MBP-NT-C2 domain or His6-MBP as also blotted on the top of the PIP strip (Echelon Biosciences) to serve as a positive control (Antibody control). Strips were blocked for $1 \mathrm{~h}$ at RT in 3\% (w/v) fatty acid-free BSA (Sigma) in TBST (50 mM Tris- $\mathrm{HCl} \mathrm{pH} \mathrm{7.5,150} \mathrm{mM} \mathrm{NaCl}$, and $0.1 \%(\mathrm{v} / \mathrm{v})$ Tween 20). PIP strips were then incubated overnight at $4{ }^{\circ} \mathrm{C}$ with gentle mixing in the blocking solution containing either $1 \mu \mathrm{g} / \mathrm{ml}$ of purified His6-MBP-NT-C2 domain or His6-MBP proteins. $1 \mathrm{mM}$ of $\mathrm{CaCl}_{2}$ was added to the control and two one of the strip while in the second strip, $5 \mathrm{mM}$ EGTA was added. The membranes were later incubated for $1 \mathrm{~h}$ with a 1:2000 dilution of anti-His antibody (Sigma) followed by three $10 \mathrm{~min}$ washing steps with TBST, and strips were then incubated with HRP goat anti-mouse antibody (Cayman chemicals) with a 1:5000 dilution. The washing steps were repeated and following development using the SuperSignal West Dura Substrate (Thermo Scientific) images were taken with a GelDoc system (Bio-Rad).

\section{Recombinant protein expression and purification. Human Rab G-domains}

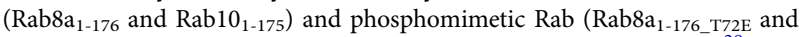
Rab10 1-175_T73E) were expressed and purified as described previously ${ }^{39}$. Rabs were preparatively loaded with GppNHp (Guanosine- $5^{\prime}$-[ $\beta$ - $\gamma$-Imido]-triphosphate) or mant GppNHp $\left(2^{\prime} / 3^{\prime}\right.$-O-N-Methyl-anthraniloyl)-guanosine- $5^{\prime}-[(\beta, \gamma)$-imido $]$ triphosphate) and the reaction was performed as described previously ${ }^{4}$. Nucleotide exchange efficiency was quantified by C18 reversed-phase column (Prontosil C18, Bischhoff Chromatography) with HPLC in $50 \mathrm{mM}$ potassium phosphate buffer $\mathrm{pH}$ 6.6, $10 \mathrm{mM}$ tetrabutylammonium bromide, and 12\% acetonitrile (v/v) and for the mant GppNHp exchange run the buffer contains $25 \%$ acetonitrile $(\mathrm{v} / \mathrm{v})$. Protein samples were heat precipitated at $95^{\circ} \mathrm{C}$ for $5 \mathrm{~min}$ and centrifuged at $15,700 \mathrm{~g}$ for $10 \mathrm{~min}$ and loaded $(25 \mu \mathrm{M}, 20 \mu \mathrm{l})$ on the column. Peaks were integrated and to determine the nucleotide retention times, a nucleotide standard run was performed.

All other proteins were recombinantly expressed in E. coli BL21 DE3-RIL (Agilent) cells in LB media supplemented with proper antibiotics and cells were grown at $37^{\circ} \mathrm{C}$ to $\mathrm{OD}_{600} \mathrm{~nm}=0.8-1.0$ and stored at $4{ }^{\circ} \mathrm{C}$ for $30 \mathrm{~min}$. Further expression was induced by the addition of $0.5 \mathrm{mM}$ IPTG, and cells were allowed to grow at $20^{\circ} \mathrm{C}$ for $14-16 \mathrm{~h}$. Cells were pelleted and stored at $-80^{\circ} \mathrm{C}$ until ready for purification. Cells were mechanically lysed by passing through a fluidizer (Microfluidic) in a buffer [ $50 \mathrm{mM}$ Hepes pH 8.0, $500 \mathrm{mM} \mathrm{NaCl}$ or LiCl, $2 \mathrm{mM} \beta \mathrm{ME}$ (2-Mercaptoethanol)] and $1 \mathrm{mM}$ PMSF (Phenylmethylsulfonyl fluoride) and lysates were cleared by centrifugation at $75,600 \mathrm{~g}$ for $30 \mathrm{~min}$. Subsequently, the proteins were purified by $\mathrm{Ni}^{2+}$-affinity chromatography (HiTrap, GE Healthcare). For the His6-MBP-NT-C2 domain purification, the protein was concentrated after first $\mathrm{Ni}^{2+}$-affinity chromatography and subjected to gel filtration (Superdex 75 26/60, GE Healthcare) in the final buffer $(20 \mathrm{mM}$ Hepes $7.5,200 \mathrm{mM} \mathrm{NaCl}$ and 2 mM DTE).

For the human EHBP1 CH, bMERB domain and other protein purifications, cells were lysed in a buffer (50 mM Hepes pH 8.0, $500 \mathrm{mM} \mathrm{NaCl}$ or $\mathrm{LiCl}$ and $2 \mathrm{mM}$ $\beta \mathrm{ME}$ (2-Mercaptoethanol) having 1\% CHAPS and lysates were cleared by centrifugation at $25,000 \mathrm{rpm}$ for $30 \mathrm{~min}$. Subsequently, the proteins were purified by $\mathrm{Ni}^{2+}$ affinity chromatography (HiTrap, GE Healthcare). The His6-tag was cleaved by Tobacco Etch Virus (TEV)-protease, and a second $\mathrm{Ni}^{2+}$-affinity purification was performed to remove the TEV protease and His6-tag. The final purification step was achieved by gel filtration (Superdex 75 26/60, GE Healthcare) (final buffer: $20 \mathrm{mM}$ Hepes 7.5 or $8.0,100 \mathrm{mM} \mathrm{NaCl}$ and $2 \mathrm{mM}$ DTE). The purified protein was collected and concentrated; flash-frozen in liquid $\mathrm{N}_{2}$, and stored at $-80^{\circ} \mathrm{C}$.

Analytical size exclusion chromatography. The bMERB:GppNHp Rab8a $a_{1-176}$ complex formation was analyzed by aSEC. $110 \mu \mathrm{M}$ of bMERB domain and $121 \mu \mathrm{M}$ of GppNHp Rab8 ${ }_{1-176}$ protein (Effector: Rab stoichiometry of 1:1.1) was mixed in a buffer containing $20 \mathrm{mM}$ Hepes $7.5,50 \mathrm{mM} \mathrm{NaCl}, 1 \mathrm{mM} \mathrm{MgCl} 2$ and $2 \mathrm{mM} \mathrm{DTE}$ (Rab buffer) and centrifuged for $15 \mathrm{~min}$ at $15,700 \mathrm{~g}$ at $4{ }^{\circ} \mathrm{C} .40 \mu \mathrm{l}$ of the mixture was injected into a Superdex $7510 / 300 \mathrm{GL}$ gel filtration column (GE Healthcare) preequilibrated with the Rab buffer with a flow rate of $0.5 \mathrm{ml} / \mathrm{min}$ at room temperature and absorption at $280 \mathrm{~nm}$ was recorded.

Similarly, the complex formation between the bMERB $(110 \mu \mathrm{M})$ domain and the $\mathrm{CH}(121 \mu \mathrm{M})$ domain was analyzed in the buffer containing $20 \mathrm{mM}$ Hepes 7.5 , $150 \mathrm{mM} \mathrm{NaCl}$, and $2 \mathrm{mM} \mathrm{DTE} \mathrm{(CH} \mathrm{buffer)} \mathrm{and} \mathrm{centrifuged} \mathrm{for} 15 \mathrm{~min}$ at $15700 \mathrm{~g}$ at $4{ }^{\circ} \mathrm{C} .40 \mu \mathrm{l}$ of the mixture was injected onto a Superdex $7510 / 300 \mathrm{GL}$ gel filtration column (GE Healthcare) pre-equilibrated with the $\mathrm{CH}$ buffer with a flow rate of $0.5 \mathrm{ml} / \mathrm{min}$ at room temperature and absorption at $280 \mathrm{~nm}$ was recorded.

Isothermal titration calorimetry. Protein-protein interaction measurements were conducted by ITC using an ITC200 microcalorimeter (MicroCal). bMERB:Rab interaction measurements were performed in buffer containing $20 \mathrm{mM}$ Hepes 7.5,
$50 \mathrm{mM} \mathrm{NaCl}, 1 \mathrm{mM} \mathrm{MgCl}_{2}$, and $1 \mathrm{mM}$ Tris (2-carboxymethyl) phosphine (TCEP) whereas bMERB: $\mathrm{CH}$ interactions were performed in buffer containing $20 \mathrm{mM}$ Hepes $7.5,150 \mathrm{mM} \mathrm{NaCl}$ and $1 \mathrm{mM}$ TCEP at $25^{\circ} \mathrm{C}$. Wild types and mutant proteins were dialyzed overnight in their respective buffer. Samples were centrifuged at $15,700 \mathrm{~g}$ for $30 \mathrm{~min}$ at $4{ }^{\circ} \mathrm{C}$ and protein concentration was determined by Bradford assay (Bio-Rad). $500 \mu \mathrm{M}$ of GppNHp Rab8 $\mathrm{a}_{1-176}$ was titrated into the cell containing $50 \mu \mathrm{M}$ bMERB domain and for bMERB:CH interaction $600-800 \mu \mathrm{M}$ of $\mathrm{CH}$ domain was titrated into the cell containing $40-60 \mu \mathrm{M}$ bMERB domain. For the control experiments, the buffer was titrated into the cell containing the bMERB domain and in the second control experiment, the $\mathrm{CH}$ domain was titrated against buffer. The binding isotherms were integrated and the data were fitted to a one-site-binding model using Origin 7.0 (MicroCal). The reported ITC result is the representative one of at least three independent measurements.

Cy3 labeling of the $\mathbf{C H}$ domain. $100 \mu \mathrm{M}$ the $\mathrm{CH}$ domain is incubated with $300 \mu \mathrm{M}$ Cy3-thioester (Jena bioscience) in the buffer containing $50 \mathrm{mM}$ Hepes $\mathrm{pH} 7.5$, $150 \mathrm{mM} \mathrm{NaCl}$ and $50 \mathrm{mM}$ MPAA (4-Mercaptophenylacetic acid, Merck) at RT for $1 \mathrm{~h}$. Free dye was removed by passing through a PD10 column (GE Healthcare) in buffer containing $50 \mathrm{mM}$ Hepes $\mathrm{pH} 7.5,150 \mathrm{mM} \mathrm{NaCl}$, and $2 \mathrm{mM}$ DTE. To check the extent of labeling, samples were analyzed by mass spectrometry (LC/ESI-MS) (Supplementary Fig. 2k).

Transient kinetic measurements. bMERB: Rab kinetic measurements were performed in Rab buffer ( $20 \mathrm{mM}$ Hepes 7.5, $50 \mathrm{mM} \mathrm{NaCl}, 1 \mathrm{mM} \mathrm{MgCl}_{2}$, and $2 \mathrm{mM}$ DTE) using a SX-20 stopped-flow apparatus (Applied Photophysics) at $25^{\circ} \mathrm{C}$. For bMERB:mantGppNHp Rab8a $a_{1-176}$ kinetic measurements, the experiments were performed using the signal from the methylanthraniloyl group of mantGppNHp, the mant group was excited with a $360 \mathrm{~nm}$ LED, and emission was detected through a $420 \mathrm{~nm}$ cutoff filter.

For bMERB:CH kinetic measurement, the experiments were performed in $\mathrm{CH}$ buffer using the signal from the $\mathrm{Cy} 3$ group of the $\mathrm{N}$-terminal $\mathrm{Cy} 3$ labeled $\mathrm{CH}$ domain and was excited with a $535 \mathrm{~nm}$ LED and emission was detected through a $570 \mathrm{~nm}$ cutoff filter. For Rab8a dissociation experiments, $\mathrm{CH}$ buffer $(20 \mathrm{mM}$ Hepes $7.5,150 \mathrm{mM} \mathrm{NaCl}$, and $2 \mathrm{mM} \mathrm{DTE}$ ) was used. All stopped-flow results that were analyzed are averages of 6-8 individual traces. Single exponential functions were fit using the Origin9 software (OriginLab).

Crystallization and structure determination. Initial crystallization condition screens for all protein complexes described in the paper were performed with the JSG Core I-IV, Pact, and Protein Complex suites (Qiagen). The sitting-drop vapor diffusion method was used, with a reservoir volume of $70 \mu \mathrm{l}$ and a drop volume of $0.1 \mu \mathrm{l}$ protein (300-400 $\mu \mathrm{M}$ complexes, 1:1 Rab:effector) and $0.1 \mu \mathrm{l}$ reservoir solution at $20^{\circ} \mathrm{C}$. The best conditions were then optimized using the sitting-drop vapor diffusion method varying drop sizes in order to obtain well diffracting crystals. The complex of bMERB $\mathrm{H}_{\mathrm{H}-2}: \mathrm{CH}(300 \mu \mathrm{M}$ of $1: 1$ complex) was crystallized in $0.18 \mathrm{M}$ Tri-ammonium citrate and $20 \%(\mathrm{w} / \mathrm{v})$ PEG 3350. The complex of bMERB $_{\text {M1116A }}:$ Rab8a $_{1-176 \_G p p N H p}(400 \mu \mathrm{M}$ of 1:1 complex) was crystallized in 0.1 Mes pH 6.0, 5\% (w/v) PEG 3000, and 30\% (v/v) PEG 200. The complex of

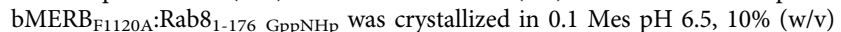
PEG-MME 5000 and $12 \%(\mathrm{v} / \mathrm{v})$ 1-Propanol. Crystals were fished directly from the crystallization drop and flash-cooled in liquid nitrogen. Diffraction data were collected at $100 \mathrm{~K}$ on beamline X10SA at the Swiss Light Source (Paul Scherrer Institute, Villigen, Switzerland). For the $\mathrm{bMERB}_{\mathrm{H} 1-2}: \mathrm{CH}$ complex crystal, a native data set was collected at a wavelength of $1.000010 \AA$ whereas two data set from a

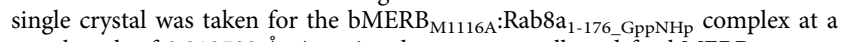
wavelength of $0.919532 \AA$. A native data set was collected for bMERB F1120A $_{\text {: }}$ : Rab8a $a_{1-176 \_G p p N H p}$ complex at a wavelength of $0.919550 \AA$. Data were integrated and scaled with XDS ${ }^{40}$

The Crystal of $\mathrm{bMERB}_{\mathrm{H} 1-2}: \mathrm{CH}$ complex diffracted to a resolution of $2.2 \AA$ (space group $\mathrm{P} 2{ }_{1}$ with $\mathrm{a}=54.06 \AA, \mathrm{b}=48.19 \AA, \mathrm{c}=100.30 \AA$ ) and two copies of the complex is present in the asymmetric unit of the crystal. The initial model for bMERB $_{\mathrm{H} 1-2}$ :CH complex was obtained by molecular replacement using PHASER ${ }^{41}$ with the NMR structure of the EHBP1 CH domain (PDB 2DK9) as a search mode ${ }^{32}$. The partial model was completed with PHENIX AutoBuild ${ }^{42}$ and manual building in $\operatorname{Coot}^{43}$. For the $\mathrm{bMERB}_{\mathrm{M} 1116 \mathrm{~A}}: \mathrm{Rab} \mathrm{a}_{1-176 \_\mathrm{GppNH}}$ complex, the crystal diffracted to a resolution of $1.914 \AA$ (space group C2 with $\mathrm{a}=116.36 \AA, \mathrm{b}=35.38$ $\AA, c=165.67 \AA$ ) and two copies of the complex constitute the asymmetric unit of the crystal. The partial model was obtained by MR using PHASER ${ }^{41}$ and the Rab8a (PDB 5SZI) was used as a search model ${ }^{4}$. The initial model was completed with PHENIX AutoBuild ${ }^{42}$ and by manual building in $\operatorname{Coot}^{43}$. The final models were refined to convergence with phenix.refine ${ }^{36}$ or Refmac $5^{44}$ of the CCP4 package ${ }^{45}$. The final model of the bMERB ${ }_{\mathrm{M} 116 \mathrm{~A}}: \mathrm{Rab}_{1-176 \mathrm{GppNHp}}$ complex was refined with phenix.refine using refined Translation/Libration/Screw tensors, which further lowered the Rfree by $9 \%$. For the bMERB $\mathrm{F}_{1120 \mathrm{~A}}: \mathrm{Rab}_{1-17 \mathrm{a}_{1} \mathrm{GppNHp}}$ complex, the crystal diffracted to a resolution of $2.0 \AA$ (space group $\mathrm{C} 2$ with $\mathrm{a}=117.34 \AA, \mathrm{b}=$ $35.66 \AA$, $c=168.56 \AA$ ) and $\mathrm{bMERB}_{\mathrm{M} 1116 \mathrm{~A}}: \mathrm{Rab}_{\mathrm{a}} \mathrm{a}_{1-176 \_ \text {GppNHp }}$ complex was used as a model for molecular replacement. 
Data collection and refinement statistics are summarized in Supplementary Table 1. Structural figures were prepared using PyMOL (DeLano Scientific; http:// www.pymol.org).

Actin co-sedimentation assay. Rabbit skeletal muscle G-actin (AKL99) was purchased from Cytoskeleton and polymerized into F-actin according to the manufacturer's protocol. F-actin $(10 \mu \mathrm{M})$ was incubated for $1 \mathrm{~h}$ at RT with different concentrations of the EHBP1 CH domain $(5-60 \mu \mathrm{M})$ in the buffer containing $5 \mathrm{mM}$ Tris-HCL pH 7.5, $0.18 \mathrm{mM} \mathrm{CaCl}_{2}, 15 \mathrm{mM} \mathrm{KCl}, 1 \mathrm{mM}$ DTT, and $1.8 \mathrm{mM}$ $\mathrm{NaN}_{3}$. Samples were centrifuged at $100,000 \mathrm{~g}$ for $1 \mathrm{~h}$ at $4{ }^{\circ} \mathrm{C}$. The supernatant and pellet were subjected to $18 \%$ SDS-PAGE, followed by Coomassie Brilliant Blue staining. The quantitative analyses were performed using the Bio-Rad image analysis software in the ChemiDoc system (Bio-Rad).

For comparative actin co-sedimentation assays, $10 \mu \mathrm{M}$ F-actin was incubated with $40 \mu \mathrm{M}$ CH domain from EHBP1, Mical1, Mical3, and Mical-L1, and cosedimentation was performed as described above.

Bioinformatics. Multiple sequence alignments were generated using Clustal Omega $^{46}$. The protein interaction interfaces from the asymmetric unit were examined in detail using the PDBePISA server (Proteins, Interfaces, Structures and Assemblies $)^{47}$. DALI server was used for structural comparison ${ }^{29}$.

Reporting summary. Further information on research design is available in the Nature Research Reporting Summary linked to this article.

\section{Data availability}

Data supporting the findings of this paper are available from the corresponding authors upon reasonable request. A reporting summary for this paper is available as a Supplementary Information file.

Protein coordinates and structure factors have been submitted to the Protein Data

Bank under accession codes

PDB 6ZSH (bMERB $\left.{ }_{\mathrm{H} 1-2}: \mathrm{CH}\right)$,

PDB 6ZSI (bMERB ${ }_{M 116 \mathrm{~A}}$ :Rab8a), and

PDB 6ZSJ (bMERB ${ }_{F 1120 A}:$ Rab8a).

Source data are provided with this paper.

Received: 25 May 2020; Accepted: 19 July 2020;

Published online: 21 August 2020

\section{References}

1. Guilherme, A., Soriano, N. A., Furcinitti, P. S. \& Czech, M. P. Role of EHD1 and EHBP1 in perinuclear sorting and insulin-regulated GLUT4 recycling in 3T3-L1 adipocytes. J. Biol. Chem. 279, 40062-40075 (2004).

2. Guilherme, A. et al. EHD2 and the novel EH domain binding protein EHBP1 couple endocytosis to the actin cytoskeleton. J. Biol. Chem. 279, 10593-10605 (2004).

3. Sano, H., Peck, G. R., Kettenbach, A. N., Gerber, S. A. \& Lienhard, G. E. Insulin-stimulated GLUT4 protein translocation in adipocytes requires the Rab10 guanine nucleotide exchange factor Dennd4C. J. Biol. Chem. 286, 16541-16545 (2011).

4. Rai, A. et al. bMERB domains are bivalent Rab8 family effectors evolved by gene duplication. Elife 5, e18675 (2016).

5. Rai, A., Goody, R. S. \& Muller, M. P. Multivalency in Rab effector interactions. Small GTPases 10, 40-46 (2019).

6. Li, Z. et al. A novel Rab10-EHBP1-EHD2 complex essential for the autophagic engulfment of lipid droplets. Sci. Adv. 2, e1601470 (2016).

7. Wang, P. et al. RAB-10 promotes EHBP-1 bridging of filamentous actin and tubular recycling endosomes. PLoS Genet. 12, e1006093 (2016).

8. Shi, A. et al. EHBP-1 functions with RAB-10 during endocytic recycling in Caenorhabditis elegans. Mol. Biol. Cell 21, 2930-2943 (2010).

9. Giagtzoglou, N., Li, T., Yamamoto, S. \& Bellen, H. J. Drosophila EHBP1 regulates Scabrous secretion during Notch-mediated lateral inhibition. J. Cell Sci. 126, 3686-3696 (2013).

10. Gudmundsson, J. et al. Common sequence variants on $2 \mathrm{p} 15$ and Xp11.22 confer susceptibility to prostate cancer. Nat. Genet. 40, 281-283 (2008).

11. Hao, Q. et al. Systematic meta-analyses of gene-specific genetic association studies in prostate cancer. Oncotarget 7, 22271-22284 (2016).

12. Ao, X. et al. Association between EHBP1 rs721048(A>G) polymorphism and prostate cancer susceptibility: a meta-analysis of 17 studies involving 150,678 subjects. Onco. Targets Ther. 8, 1671-1680 (2015).

13. Leong, K. G. \& Gao, W. Q. The Notch pathway in prostate development and cancer. Differentiation 76, 699-716 (2008).
14. Ghalali, A., Wiklund, F., Zheng, H., Stenius, U. \& Hogberg, J. Atorvastatin prevents ATP-driven invasiveness via P2X7 and EHBP1 signaling in PTENexpressing prostate cancer cells. Carcinogenesis 35, 1547-1555 (2014).

15. Zhang, D. \& Aravind, L. Identification of novel families and classification of the C2 domain superfamily elucidate the origin and evolution of membrane targeting activities in eukaryotes. Gene 469, 18-30 (2010).

16. Corbalan-Garcia, S. \& Gomez-Fernandez, J. C. Signaling through C2 domains more than one lipid target. Biochim. Biophys. Acta 1838, 1536-1547 (2014).

17. Steger, M. et al. Phosphoproteomics reveals that Parkinson's disease kinase LRRK2 regulates a subset of Rab GTPases. Elife 5, e12813 (2016).

18. Steger, M. et al. Systematic proteomic analysis of LRRK2-mediated Rab GTPase phosphorylation establishes a connection to ciliogenesis. Elife 6, e31012 (2017)

19. Giridharan, S. S., Rohn, J. L., Naslavsky, N. \& Caplan, S. Differential regulation of actin microfilaments by human MICAL proteins. J. Cell Sci. 125, 614-624 (2012).

20. Schmidt, E. F., Shim, S. O. \& Strittmatter, S. M. Release of MICAL autoinhibition by semaphorin-plexin signaling promotes interaction with collapsin response mediator protein. J. Neurosci. 28, 2287-2297 (2008).

21. Abou-Zeid, N. et al. MICAL-like1 mediates epidermal growth factor receptor endocytosis. Mol. Biol. Cell 22, 3431-3441 (2011).

22. Sakane, A. et al. Conformational plasticity of JRAB/MICAL-L2 provides "law and order" in collective cell migration. Mol. Biol. Cell 27, 3095-3108 (2016).

23. Miyake, K. et al. Actin cytoskeletal reorganization function of JRAB/MICAL L2 is fine-tuned by intramolecular interaction between first LIM zinc finger and C-terminal coiled-coil domains. Sci. Rep. 9, 12794 (2019).

24. Fremont, S. et al. Oxidation of F-actin controls the terminal steps of cytokinesis. Nat. Commun. 8, 14528 (2017).

25. Gimona, M., Djinovic-Carugo, K., Kranewitter, W. J. \& Winder, S. J. Functional plasticity of $\mathrm{CH}$ domains. FEBS Lett. 513, 98-106 (2002).

26. Sjoblom, B., Ylanne, J. \& Djinovic-Carugo, K. Novel structural insights into F-actin-binding and novel functions of calponin homology domains. Curr. Opin. Struct. Biol. 18, 702-708 (2008).

27. Singh, S. M., Bandi, S., Winder, S. J. \& Mallela, K. M. The actin binding affinity of the utrophin tandem calponin-homology domain is primarily determined by its N-terminal domain. Biochemistry 53, 1801-1809 (2014).

28. Way, M., Pope, B. \& Weeds, A. G. Evidence for functional homology in the F-actin binding domains of gelsolin and alpha-actinin: implications for the requirements of severing and capping. J. Cell Biol. 119, 835-842 (1992).

29. Holm, L. Benchmarking fold detection by DaliLite v.5. Bioinformatics 35 5326-5327 (2019)

30. Lee, S. H., Weins, A., Hayes, D. B., Pollak, M. R. \& Dominguez, R. Crystal structure of the actin-binding domain of alpha-actinin-4 Lys255Glu mutant implicated in focal segmental glomerulosclerosis. J. Mol. Biol. 376, 317-324 (2008).

31. Djinovic Carugo, K., Banuelos, S. \& Saraste, M. Crystal structure of a calponin homology domain. Nat. Struct. Biol. 4, 175-179 (1997).

32. Tomizawa, T., Kigawa, T., Koshiba, S., Inoue, M. \& Yokoyama, S. Solution structure of the $\mathrm{CH}$ domain from human $\mathrm{EH}$ domain binding protein 1 . https://doi.org/10.2210/pdb2D89/pdb (2006).

33. Khan, A. R. \& Menetrey, J. Structural biology of Arf and Rab GTPases' effector recruitment and specificity. Structure 21, 1284-1297 (2013).

34. Iwamoto, D. V. et al. Structural basis of the filamin A actin-binding domain interaction with F-actin. Nat. Struct. Mol. Biol. 25, 918-927 (2018).

35. Schrödinger Release 2020-1. MacroModel, Schrödinger, LLC, (New York, NY, 2020).

36. Adams, P. D. et al. PHENIX: a comprehensive Python-based system for macromolecular structure solution. Acta Crystallogr. D. Biol. Crystallogr. 66, 213-221 (2010)

37. Vieweg, S. et al. PINK1-dependent phosphorylation of Serine111 within the SF3 motif of Rab GTPases impairs effector interactions and LRRK2 mediated phosphorylation at Threonine72. Biochem. J. 477, 1651-1668 (2020).

38. Waschbusch, D. et al. Structural Basis for Rab8a Recruitment of RILPL2 via LRRK2 Phosphorylation of Switch 2. Structure. 28, 406-417 (2020).

39. Bleimling, N., Alexandrov, K., Goody, R. \& Itzen, A. Chaperone-assisted production of active human Rab8A GTPase in Escherichia coli. Protein Expr. Purif. 65, 190-195 (2009)

40. Kabsch, W. Xds. Acta Crystallogr. D. Biol. Crystallogr. 66, 125-132 (2010).

41. McCoy, A. J. et al. Phaser crystallographic software. J. Appl Crystallogr. 40, 658-674 (2007)

42. Terwilliger, T. C. et al. Iterative model building, structure refinement and density modification with the PHENIX AutoBuild wizard. Acta Crystallogr. D. Biol. Crystallogr. 64, 61-69 (2008).

43. Emsley, P., Lohkamp, B., Scott, W. G. \& Cowtan, K. Features and development of Coot. Acta Crystallogr. D. Biol. Crystallogr. 66, 486-501 (2010).

44. Murshudov, G. N., Vagin, A. A. \& Dodson, E. J. Refinement of macromolecular structures by the maximum-likelihood method. Acta Crystallogr. D. Biol. Crystallogr. 53, 240-255 (1997). 
45. Winn, M. D. et al. Overview of the CCP4 suite and current developments. Acta Crystallogr. D. Biol. Crystallogr. 67, 235-242 (2011).

46. Sievers, F. et al. Fast, scalable generation of high-quality protein multiple sequence alignments using Clustal Omega. Mol. Syst. Biol. 7, 539 (2011).

47. Krissinel, E. \& Henrick, K. Inference of macromolecular assemblies from crystalline state. J. Mol. Biol. 372, 774-797 (2007).

\section{Acknowledgements}

We thank the Swiss Light Source (SLS) X10SA beamline staff for the opportunity of collecting data at the Paul Scherrer Institute, Villigen, Switzerland. We thank the X-ray community at the Max Planck Institute Dortmund and Dr. Raphael Gasper-

Schönenbrücher for help with data collection. We are indebted to Dr. Emerich Mihai Gazdag and Dr. Matthias Müller for their helpful discussion and help in X-ray crystallography. Many thanks go to Georg Holtermann for his technical support in X-ray crystallography and in-house data collection. We thank Jeremy Campos for providing Mical-L1 bMERB construct. We acknowledge financial support from the Max-PlanckSociety and from the Deutsche Forschungsgemeinschaft (grant GO 284/10-1). Open access funding provided by Projekt DEAL.

\section{Author contributions}

A.R. and R.S.G. conceived and designed the study. A.R. and N.B. carried out protein expression/purification. A.R. carried out all biochemical studies, in vivo localization experiments, and crystallization work. N.B. performed lipid overlay assay and actin-cosedimentation assay. A.R. and I.V. determined the X-ray-structures. I.V. performed molecular modeling. A.R., I.V., and R.S.G. analyzed and interpreted the data. A.R., I.V., and R.S.G. wrote the paper.

\section{Competing interests}

The authors declare no competing interests.

\section{Additional information}

Supplementary information is available for this paper at https://doi.org/10.1038/s41467020-17792-3.

Correspondence and requests for materials should be addressed to A.R. or R.S.G.

Peer review information Nature Communications thanks David Lambright and Angela Wandinger-Ness for their contributions to the peer review of this work. Peer review reports are available.

Reprints and permission information is available at http://www.nature.com/reprints

Publisher's note Springer Nature remains neutral with regard to jurisdictional claims in published maps and institutional affiliations.

\section{(c) (i)}

Open Access This article is licensed under a Creative Commons Attribution 4.0 International License, which permits use, sharing, adaptation, distribution and reproduction in any medium or format, as long as you give appropriate credit to the original author(s) and the source, provide a link to the Creative Commons license, and indicate if changes were made. The images or other third party material in this article are included in the article's Creative Commons license, unless indicated otherwise in a credit line to the material. If material is not included in the article's Creative Commons license and your intended use is not permitted by statutory regulation or exceeds the permitted use, you will need to obtain permission directly from the copyright holder. To view a copy of this license, visit http://creativecommons.org/ licenses/by/4.0/.

(C) The Author(s) 2020 